\title{
Determinant factors of cloud-sourcing decisions: reflecting on the IT outsourcing literature in the era of cloud computing
}

\author{
Stephan Schneider, Ali Sunyaev \\ University of Cologne, Cologne, Germany \\ Correspondence: \\ Ali Sunyaev, University of Cologne, Pohligstraße 1, 50969 Cologne, Germany. \\ Tel: +49-221-470-5397; \\ Fax: +49-221-470-5386; \\ E-mail: sunyaev@wiso.uni-koeln.de
}

\begin{abstract}
Cloud computing (CC) is an emerging form of IT outsourcing (ITO) that requires organizations to adjust their sourcing processes. Although ITO researchers have established an extensive knowledge base on the determinant factors that drive sourcing decisions from various theoretical perspectives, the majority of research on cloud-sourcing decisions focuses on technological aspects. We reviewed the CC and ITO literature and systematically coded the determinant factors that influence sourcing decisions. We show that most determinant factors of sourcing decisions in the ITO context remain valid for the CC context. However, the findings for some factors (i.e., asset specificity, client firm IT capabilities, client firm size, institutional influences, and uncertainty) are inconclusive for the CC and ITO contexts. We discuss how the peculiarities of CC can explain these inconclusive findings. Our results indicate that $C C$ researchers should draw from research on ITO decision making but re-examine ITO concepts in the light of the peculiarities of CC, such as the differences between software and infrastructure services, the self-service procurement of cloud services, or the evolving role of IT departments. By summarizing determinant factors of cloud-sourcing decisions for consideration in future research, we contribute to the development of endogenous theories in the IS domain.
\end{abstract}

Journal of Information Technology (2016) 31, 1-31. doi:10.1057/jit.2014.25;

published online 11 November 2014

Keywords: cloud computing; IT outsourcing; sourcing decision; determinant factors; adoption; literature review

\section{Introduction}

C loud computing (CC) changes how organizations manage their IT landscape, challenges traditional IT governance approaches, and requires organizations to adjust their sourcing processes (Yanosky, 2008; Armbrust et al., 2010; Winkler and Brown, 2013; Ragowsky et al., 2014). With CC, organizations can gain on-demand network access to a shared pool of managed and scalable IT resources, such as servers, storage, and applications (Mell and Grance, 2011). Because IT sourcing decisions entail substantial economic and strategic risks (Martens and Teuteberg, 2009; Benlian and Hess, 2011), managers must have extensive judgment and insight regarding organizational structures, interdependencies, processes, and habits to thoroughly comprehend decision alternatives and the set of required structural choices (McIvor and Humphreys, 2000; Cullen et al., 2005; Moses and Åhlström, 2008; Aubert et al., 2012). However, empirical insight into cloud-sourcing decisions remains scarce (Yang and Tate, 2012).

CC is an evolution and specific form of IT outsourcing (ITO); thus, the extensive body of research on ITO provides a valuable basis for investigating cloud-sourcing decisions. During the last two decades, IS researchers have applied various economic, strategic, organizational, and social theories to identify determinant factors that drive ITO and have produced a considerable body of knowledge on ITO decision making (Dibbern et al., 2004; Lacity et al., 2010). However, rather than leveraging this insightful body of knowledge on ITO, the majority of research on the determinant factors of cloud-sourcing decisions focuses on technological aspects of $\mathrm{CC}$ and their implications for decision making (e.g., Koehler et al., 2010; Wu et al., 2011; Brender and Markov, 2013; Gupta et al., 2013; McGeogh and Donnellan, 2013). 
The few studies that apply a broader theoretical perspective predominantly draw on transaction cost economics (TCE) (e.g., Benlian et al., 2009; Asatiani et al., 2014). However, traditional, purely economic factors cannot sufficiently explain sourcing decisions for IT services (Vetter et al., 2011; Bidwell, 2012), as the 'ITO phenomenon is more complex than can be accommodated by one decision-making theory' (Lacity et al., 2011: 140). Hence, IT sourcing decisions need to be investigated using an integrative research model from multiple theoretical perspectives (Tiwana and Bush, 2007; Benlian et al., 2009; Lacity et al., 2011).

CC and ITO share basic principles, benefits, and challenges (Leimeister et al., 2010; Benlian and Hess, 2011). However, CC bears certain peculiarities, such as shifting task responsibilities, on-demand self-service procurement, advanced governance approaches, and short-term usage-based contracts for standardized services (Susarla et al., 2010; Benlian and Hess, 2011; Malladi and Krishnan, 2012; Chen and Wu, 2013), which require an examination of the ITO literature in the context of CC. This article accordingly aims to identify determinant factors of cloud-sourcing decisions that proved to be robust in extant research on CC and ITO. Specifically, we address the following two research questions: RQ1: What can we learn from the rich body of research on ITO to identify determinant factors of cloud-sourcing decisions? RQ2: Are there differences between the determinant factors of ITO decisions and the determinant factors of cloud-sourcing decisions, and if so, do the peculiarities of CC explain these differences?

To derive determinant factors of cloud-sourcing decisions, we conducted a systematic review of the CC and ITO literature until April 2014 and identified 88 articles that empirically examined IT sourcing decisions. By applying the method of Jeyaraj et al. (2006) to systematically code and aggregate the determinant factors that influence decision making, we aggregated findings from both quantitative and qualitative research. We extracted 111 determinant factors and coded 542 relationships describing the influence of these factors on decision making. Further, to identify differences between the determinant factors of ITO decisions and the determinant factors of cloud-sourcing decisions, we divided the coded relationships into relationships applicable to ITO and relationships applicable to $\mathrm{CC}$. We then compared and contrasted results within the ITO literature with results within the CC literature and identified (i) factors with consistent empirical evidence for CC, (ii) factors with consistent empirical evidence for ITO or the overall sample but only limited evidence for CC, and (iii) factors with inconclusive empirical evidence for $\mathrm{CC}$ and ITO. In this article, we discuss whether the peculiarities of CC explain the inconclusive results. Based on our discussion, we derive a set of determinant factors of cloud-sourcing decisions that have proved to be robust in extant research on CC and ITO. Accordingly, we explain which findings from ITO research are applicable to $\mathrm{CC}$ and which findings may require reconsideration in the era of CC.

This review answers the appeal of Lacity et al. (2011: 147), who call for the development of an 'endogenous ITO theory rather than continuing to rely heavily on reference discipline theories'. We draw from research within the IS community, endogenously derive determinant factors of cloud-sourcing decisions, and discuss our findings through the lens of CC peculiarities. In this manner, our results provide a basis for future research and contribute to the development of endogenous theories in the IS domain. Researchers can draw from our derived set of determinant factors of cloud-sourcing decisions to advance research on decision making or acquisition in the field of CC. Practitioners may use the set of determinant factors to guide their procurement processes and to identify challenges that may arise during the adoption, acquisition, or integration of cloud services.

The remainder of this article is organized as follows: first, we provide a background on CC and IT sourcing decisions. We then describe the research method and discuss our findings. We close with a discussion of the implications of our work for future research, the limitations of our work, and a conclusion.

\section{Background}

This section defines the CC sourcing model and our unit of analysis. We then differentiate this literature review from existing literature reviews on CC and distinguish CC from ITO to provide a basis for the discussion of our findings.

\section{Cloud computing}

CC provides on-demand network access to a shared pool of managed and scalable IT resources on a pay-per-use basis (Mell and Grance, 2011). IT resources refer to hardware (Infrastructure as a Service, IaaS), development platforms (Platform as a Service, PaaS), and applications (Software as a Service, SaaS), and they 'can be rapidly provisioned and released with minimal management effort or service provider interaction' (Mell and Grance, 2011: 3). Customers do not own, manage, or operate the underlying infrastructure, platform, or application capabilities but rather access resources remotely through the Internet (Mell and Grance, 2011). The benefits of CC include up-to-date IT resources on a pay-peruse basis with a high degree of flexibility and low upfront capital investment (Armbrust et al., 2010). Research on CC has broadly adopted the CC definition of Mell and Grance (2011), who distinguish five key characteristics, three service models (IaaS, PaaS, and SaaS), and four deployment models (private, public, community, and hybrid cloud). The five key characteristics are the provision of (i) on-demand self-service access to (ii) virtualized, shared, and managed IT resources that are (iii) scalable on-demand, (iv) available over a network, and (v) priced on a pay-per-use basis.

IaaS provides virtualized computing resources (e.g., servers, storage, networks) on which users can deploy, control, and run arbitrary software (including operating systems and applications), but users do not own, manage, and operate these virtualized computing resources (Mell and Grance, 2011). Examples of such services include Amazon EC2 and Rackspace Cloud. PaaS offers a highly integrated environment in which to design, build, test, and deploy custom applications (Foster et al., 2008) 'without the cost and complexity of buying and managing the underlying hardware and software layers' (Marston et al., 2011: 178) but with benefits from features such as 'automatic scaling and load balancing, authentication services, communication services or graphical user interface (GUI) components' (Leimeister et al., 2010: 5). Examples of these services include Microsoft Azure and Google App Engine. SaaS provides software applications that run on cloud infrastructures, that are remotely accessible through the Internet, and that are typically accessed by end users via a thin 
client interface (e.g., a web browser). In the context of SaaS, users do not own, manage, or operate the underlying infrastructure, platform, or even individual application capabilities (Mell and Grance, 2011). Examples range from complex enterprise applications, such as SAP Business ByDesign, to office, email, and collaboration services, such as Google Apps.

Public clouds are owned, managed, and operated by external providers and are made available to the general public over the Internet (Armbrust et al., 2010: 50), whereas private clouds are 'provisioned for exclusive use by a single organization' (Mell and Grance, 2011: 3) and are not available to the general public. However, given clouds' public availability, security and privacy have become important concerns in public CC (European Network and Information Security Agency, 2011; Jansen and Grance, 2011). Private clouds are 'easier to align with security, compliance, and regulatory requirements [than public clouds]' (Ramgovind et al., 2010: 2), but they offer fewer benefits, for example, in terms of cost reduction and scalability. Mixed forms of private and public clouds aim to combine the benefits of both public and private clouds. Community clouds are 'controlled and used by a group of organizations that have shared interests, such as specific security requirements' (Marston et al., 2011: 180), where 'its strengths and weaknesses fall between those of a private cloud and those of a public one' (European Network and Information Security Agency, 2011: 55). Hybrid clouds are a combination of public and private cloud services; 'typically, noncritical information is outsourced to the public cloud, while business-critical services and data are kept within the control of the organization' (Marston et al., 2011: 180).

During recent years, CC has received enormous attention from academics and practitioners, resulting in a disparate collection of publications from research and practice. To synthesize the body of knowledge on CC, researchers have conducted literature reviews that provide a general overview of CC research (Yang and Tate, 2012), that focus on a specific domain (Ermakova et al., 2013), or that focus on particular aspects, such as security (Khorshed et al., 2012). However, this study is the first to survey and synthesize the literature on IT sourcing decisions, to discuss differences between findings on CC and ITO, and to derive determinant factors of cloudsourcing decisions. To distinguish this literature review from previous literature reviews, an overview of existing literature reviews on CC is presented in Appendix A.

\section{Cloud-sourcing decisions}

The unit of analysis in this article is determinant factors of cloud-sourcing decisions. We define a cloud-sourcing decision as an organization's decision to adopt and integrate cloud services from external providers into their IT landscape, that is, the customer organization's assessment of CC offerings from one or more providers in any form of service model (IaaS, PaaS, SaaS) or deployment model (public, private, community, hybrid). We thereby explicitly exclude organizational (internal) activities related to data center virtualization and IT services provided by an internal IT department.

Concerning IT sourcing decisions, researchers have investigated a range of dependent constructs, including the intention to increase the level of SaaS adoption' (Benlian and Hess, 2011), 'ASP adoption intention' (Yao et al., 2010), 'netsourcing decision' (Loebbecke and Huyskens, 2006), or the 'degree of IS outsourcing'
(Ang and Straub, 1998). These examples highlight researchers' use of different constructs to denote adoption decisions of various sourcing options (e.g., CC, ASP, ITO). In our work, we follow Lacity et al. $(2010,2011)$ and use one meta-construct to subsume these constructs, that is, the IT sourcing decision.

\section{Cloud computing as new form of ITO}

ITO can be defined as 'the significant contribution by external vendors in the physical and/or human resources associated with the entire or specific components of the IT infrastructure in the user organization' (Loh and Venkatraman, 1992a: 9). Cost advantages, flexibility, and competitive advantages are possible benefits that have made ITO one of the most important strategic concepts in recent decades (Leimeister et al., 2010) and an intensively studied field within IS research (Dibbern et al., 2004; Lacity et al., 2010).

Application service provision (ASP) is a 'form of outsourcing, specifically selective outsourcing, where firms rent packaged software and associated services from a third party' (Bennett and Timbrell, 2000: 196). Jayatilaka et al. (2003) extend this definition and define ASP as an IS application service that is offered, hosted, and managed by a vendor on a rental basis. Researchers argue that SaaS emerged as an advanced form of ASP (Heart, 2010; Benlian and Hess, 2011) and that CC "has the same key attributes as the "standard" ASP model, and exposes the user to the same risks' (Schwarz et al., 2009: 774). The definitions of ASP and SaaS as well as their similarities in strategic, technical, and economic opportunities and risks (Kern et al., 2002; Schwarz et al., 2009; Armbrust et al., 2010; Marston et al., 2011) support this proposition. Furthermore, both ASP and SaaS share similar business and pricing models (Weinhardt et al., 2009). Given the purpose of this research and the similarities between ASP and SaaS, we consider SaaS to be an advanced form of ASP and do not further differentiate these two sourcing options.

CC and ITO share common characteristics and provide similar benefits to users; research findings on ITO adoption are thus applicable to CC adoption to a certain extent (Benlian and Hess, 2011; Malladi and Krishnan, 2012; Chen and Wu, 2013). However, certain peculiarities regarding CC distinguish it from ITO and therefore induce the need to re-examine the determinant factors of sourcing decisions for CC. For instance, compared with traditional ITO, CC induces a shift in task responsibilities during decision processes and self-service procurement, provides standardized services with a narrower scope, enables new scenarios of outsourcing and governance arrangements, and uses short-term usage-based contracts (Susarla et al., 2010; Benlian and Hess, 2011; Malladi and Krishnan, 2012; Chen and $\mathrm{Wu}, 2013$ ). Table 1 summarizes the major differences between CC and ITO.

To determine what we can learn from the rich body of research on ITO and to identify determinant factors of cloudsourcing decisions, we use the arguments listed in Table 1 as analytical devices to discuss the differences identified in the literature between CC-related findings and ITO-related findings. Therefore, we first survey the literature and aggregate the existing research on IT sourcing decisions. The next section describes our literature search, selection, and coding methods.

\section{Research method}

In this section, we first describe the scope of the literature review and the criteria that we applied to identify the 88 
Table 1 Comparison of cloud computing and IT outsourcing

\begin{tabular}{|c|c|c|}
\hline & Cloud computing & IT outsourcing \\
\hline Scope & $\begin{array}{l}\text { - Standardized software (SaaS) or cloud } \\
\text { infrastructures (IaaS/PaaS) created by } \\
\text { the provider for an anonymous market } \\
\text { - Role of the IT department as service integrator } \\
\text { - Limited customization }\end{array}$ & $\begin{array}{l}\text { - Custom-tailored IT services } \\
\text { - Can include hardware, software, people, and processes } \\
\text { (e.g., software development, datacenter operations, desktop } \\
\text { maintenance, help desk operations) }\end{array}$ \\
\hline Ownership & $\begin{array}{l}\text { - Outsourced assets totally owned by the provider } \\
\text { and its providers }\end{array}$ & $\begin{array}{l}\text { - Varies with type and degree of outsourcing } \\
\text { - Totally owned by the customer } \\
\text { - Partially owned by the customer } \\
\text { - Totally owned by the provider }\end{array}$ \\
\hline Contractual mode & $\begin{array}{l}\text { - Short term } \\
\text { - Usage based } \\
\text { - High degree of automation and scaling } \\
\text { - Minimal up-front costs } \\
\text { - Little possibility for negotiation, standardized } \\
\text { terms of use }\end{array}$ & $\begin{array}{l}\text { - Long term } \\
\text { - Period based or project based } \\
\text { - Individually negotiated } \\
\text { - Pricing based on business metrics } \\
\text { - Strategic partnerships for continuous and joint innovation }\end{array}$ \\
\hline Environment & $\begin{array}{l}\text { - Decentralized market } \\
\text { - Volatile and immature market } \\
\text { - Uncertain legal issues }\end{array}$ & $\begin{array}{l}\text { - Outsourcing market is well established with numerous } \\
\text { experienced providers }\end{array}$ \\
\hline Broad network access & $\begin{array}{l}\text { - Critical network dependence } \\
\text { - Potential bottlenecks, slowdowns, and outages that } \\
\text { neither the client nor the vendor can control }\end{array}$ & $\begin{array}{l}\text { - Depends on the type of outsourcing (e.g., less critical for } \\
\text { software development than for datacenter operations) }\end{array}$ \\
\hline Resource pooling & $\begin{array}{l}\text { - Multi-tenant virtualized applications } \\
\text { - Common code stack } \\
\text { - Provider-determined upgrade schedule }\end{array}$ & - None \\
\hline
\end{tabular}

Note: This table was constructed based on the following: (Loh and Venkatraman, 1992a; Lacity and Hirschheim, 1993a; Bennett and Timbrell, 2000; Kakabadse and Kakabadse, 2002; Kern et al., 2002; Jayatilaka et al., 2003; Morabito, 2003; Serva et al., 2003; Dibbern et al., 2004; Narayandas, 2005; Dhar and Balakrishnan, 2006; Pollock and Williams, 2007; Xin and Levina, 2008; Benlian et al., 2009; Schwarz et al., 2009; Susarla et al., 2010; Benlian and Hess, 2011; Martens and Teuteberg, 2011; Marston et al., 2011; Mell and Grance, 2011; Vetter et al., 2011; Giessmann and Stanoevska, 2012; Malladi and Krishnan, 2012; Lacity and Willcocks, 2013; Sunyaev and Schneider, 2013; Wollersheim et al., 2013; Ragowsky et al., 2014). 
relevant articles that were published before April 2014. We then explain the applied method to code and aggregate the determinant factors of IT sourcing decisions.

\section{Scope of the review}

To ensure a high-quality literature review, we followed the guidelines by Webster and Watson (2002). This structured approach assumes that the major contributions in a research field are primarily found in journals of high reputation and quality. Therefore, we considered the Senior Scholars' Basket of Journals (Association for Information Systems, 2011) and the top 50 journals (including selected ACM/IEEE Transactions) of the AIS journal ranking (Association for Information Systems, 2005). To include the latest research on CC but still focus on high-quality contributions, we broadened the scope by additionally considering leading conferences of the IS community. The peer selection of outlets considered in this literature review consisted of 68 journals and 3 conferences (see Appendix B). We aimed to gather all contributions dedicated to CC or related paradigms that focus on sourcing decisions. We therefore searched publications by title, keywords, and abstract using the following list of keywords: (Cloud OR IaaS OR PaaS OR SaaS OR XaaS OR 'Infrastructure as a Service' OR 'Platform as a Service' OR 'Software as a Service' OR 'IT service' OR 'Application Service' OR ASP OR Outsourcing) AND (Adoption OR Assimilation OR Choice OR Decision OR Determinant OR Diffusion OR Driver OR Infusion OR Inhibitor OR Option OR Select OR Usage OR Use).

\section{Inclusion and exclusion criteria}

We included only completed peer-reviewed research articles that empirically investigate organizational sourcing decisions in the context of CC, ASP, or ITO and excluded conceptual articles, news articles, and reviews of prior research. To transfer findings from the ITO context to the CC context and to discuss what the literature on cloud-sourcing decisions can learn from the literature on ITO decisions (i.e., which findings are transferable to the CC context and which findings might require reconsideration), we had to limit the context of the ITO articles included to a common denominator. Therefore, studies concerning ITO were included only if they investigate sourcing decisions that are similar to sourcing decisions for cloud services. We used the following inclusion criteria for the selection process:

\section{Applicability to CC}

When considering articles concerning ITO, we referred to the descriptive ITO framework of de Looff (1995), who describes which parts of an organization's IT function are outsourced according to three dimensions:

- functional information systems (the business process that a system supports or controls, such as customer relationship management or order scheduling);

- components (hardware, software, data, personnel, and procedures); and

- activities (planning, development, implementation, maintenance, and operation).

For example, an organization can outsource the development of the software for a customer relationship management system. To include only outsourcing types that are comparable to sourcing decisions concerning one of the three cloud service models (IaaS, PaaS, and SaaS), we included only articles that investigate selective outsourcing of at least the maintenance and operation of the hardware or software of any functional information system to an external provider while keeping the business process itself in-house. Therefore, we excluded, for example, research focusing on software development, help desk, desktop maintenance, or business process outsourcing, as these types of outsourcing are specific in terms of the associated managerial problems, required capabilities, and implications for the workforce (Lacity and Hirschheim, 1993b; Baldwin et al., 2001; Wholey et al., 2001). For studies that investigate the outsourcing of multiple functions and that distinguish their results according to outsourced functions, we referred to the subsample and results of the outsourced function that is similar to CC (e.g., we used the subsample of 'system \& data center operations' in Dibbern and Heinzl (2009)).

\section{External services}

This research focuses on services delivered by external providers. We excluded organizational (internal) activities related to data center virtualization and IT services provided by the internal IT department, as the managerial implications of internal IT service provision differ from those of outsourcing. For instance, internally delivered cloud services are easier to align with security, compliance, legal, and regulatory requirements than externally delivered cloud services (European Network and Information Security Agency, 2011). Thus, inhibitors such as data location (Browning and MacDonald, 2011), vendor lock-in (Armbrust et al., 2010), and loss of control (Spink, 2010) play a subordinate role in internal cloud service provision.

\section{Private sector}

Because certain factors play a significant role in public sector sourcing decisions but not in private sector sourcing decisions (Arlbjørn and Freytag, 2012), we included only articles that investigate sourcing decisions for private sector organizations. For instance, only cloud service providers that are certified by the Federal Risk and Authorization Management Program (FedRAMP) are allowed to provide cloud services for US public sector organizations (General Services Administration, 2012). Furthermore, specific laws and regulations apply (e.g., the Federal Information Security Management Act of 2002; Title 44 US Code $\$ 3541$, et seq.), and different stakeholders or forces have a voice in public sector sourcing decisions (e.g., the government). Thus, to retain focus on a similar set of outsourcing decisions, we excluded public sector studies (e.g., Janssen and Joha, 2011).

\section{Identification of 88 empirical articles on IT sourcing decisions}

Execution of the search string and application of the defined inclusion criteria resulted in 48 relevant articles. Backward search (14 relevant articles) and forward search (14 relevant articles) were conducted subsequently. Additionally, we conducted a backward search on selected CC and ITO literature reviews (Lacity et al., 2009; Martens and Teuteberg, 2009; Lacity et al., 2010, 2011; Venters and Whitley, 2012; Yang and Tate, 2012) and identified 12 additional relevant articles. Thus, the total set of articles considered in this literature review includes 88 articles that have been published before April 2014 
without limiting the time frame (see Appendix $\mathrm{C}$ for a list of all articles). In total, 60 articles (68\%) are quantitative, and 28 are qualitative (32\%). The majority of the articles originate from the ITO research stream (45 articles, $51 \%$ ). ASP is the focus of 20 articles (23\%), and CC is the focus of 23 articles $(26 \%), 12$ of which are dedicated to SaaS and 11 of which are dedicated to general CC.

\section{Variable coding}

We coded the 88 relevant articles based on the method developed by Jeyaraj et al. (2006) and applied to the ITO context by Lacity et al. $(2010,2011)$. The applied method enabled us to include results from both qualitative and quantitative studies. To aggregate the findings across studies, we adapted the iterative method of Lacity et al. (2010) that requires individual articles to be coded multiple times. In each iteration, we followed a three-step approach to examine a set of 20 randomly selected articles. To ensure consistent coding, two researchers independently coded all of the articles and discussed any conflicting results after each iteration.

\section{Step 1: Code author variables}

For each independent and dependent variable in an article, we coded the name and definition as given by the authors ('author variable' and 'author variable definition').

\section{Step 2: Code relationships}

We coded each examined relationship between the independent and dependent variables. To uniformly code the relationships between the independent and dependent variables from qualitative and quantitative studies, we applied the coding template of Lacity et al. (2010), which is depicted in Table 2. For each relationship, one of four possible values was assigned $(+,-, \mathrm{M}, 0)$.

\section{Step 3: Code master variables}

We independently combined and aggregated the coded author variables (see step 1) and developed a set of 'master variables' and 'master variable definitions' (see Appendix E for the variable definitions). Each researcher independently mapped the author variables of the 20 articles on the master variables. The master variables were complemented by new master variables in each iteration. If new variables were added, then previously coded articles were re-examined to determine whether any variables needed to be refined based on the addition of the new master variables. After each iteration, we met and discussed the master variables and relationship coding. Variable definitions as well as conflicting mappings and relationships were discussed and adapted. This process continued until all of the articles were coded.

\section{Verification of coding and grouping of master variables}

One researcher conducted a final check through all of the articles and coded relationships to ensure that all of the variables were coded consistently with the master variable list. For consistency checks, each master variable definition was cross-checked with the definitions of all of the author variables mapped on the master variable as well as the definitions from seminal theoretical articles (e.g., Williamson (1981) for asset specificity).

To facilitate discussion of a large number of variables that cover diverse facets of IT sourcing, we categorized the variables into seven broader categories. We divided the factors into the following categories: asset characteristics, technology characteristics, solution characteristics, client firm characteristics, individual characteristics of the decision maker, environmental characteristics, and vendor firm characteristics. The variables and categories evolved inductively from the literature.

\section{Identification of determinant factors of cloud-sourcing decisions}

To identify the determinant factors of cloud-sourcing decisions with consistent results in previous research, we counted the number of times that the relationship between a master variable and the dependent meta-variable IT sourcing decision was studied and the number of times that this relationship is reported to be positively significant, negatively significant, nonsignificant, or significant but non-directional (e.g.) categorical variables, see Table 2). Next, we applied the decision rule of Lacity et al. (2010) and identified master variables that have been examined multiple times and that have produced consistent results. In terms of multiple examinations, we extracted all of the master variables that were empirically examined to influence sourcing decisions at least five times. In terms of consistent results, we selected only master variables for which at least $60 \%$ of the findings are consistent (i.e., significantly positive, significantly negative, or significant but non-directional). This minimum threshold ensures that more than half of the evidence produced the same findings.

We then divided our coding results into two batches. The first batch consists of coded relationships between the master variables and sourcing decisions in the ITO context, and the second batch consists of coded relationships between the

Table 2 Relationship coding scheme, adapted from Lacity et al. (2010)

Code Meaning

$+\quad$ Positive relationship: a higher value of the independent variable is associated with a higher value of the dependent variable; $P<0.05$ for quantitative studies or strong argument by authors for qualitative studies

- Negative relationship: a higher value of the independent variable is associated with a lower value of the dependent variable; $P<0.05$ for quantitative studies or strong argument by authors for qualitative studies

M The relationship matters: the relationship between a categorical independent variable (e.g., industry) and a dependent variable is significant but non-directional; $P<0.05$ for quantitative studies or strong argument by authors for qualitative studies

$0 \quad$ Relationship was studied and no significant relationship was found 
master variables and sourcing decisions in the CC context (including ASP because we treated ASP as form of SaaS; see background section). We assessed each extracted master variable by comparing and contrasting the coded relationships for CC and ITO. The next section reports the results of our assessment and presents the factors with consistent empirical evidence for CC, the factors with consistent empirical evidence for ITO but only limited evidence for CC, and the factors with contradicting or inconclusive findings in the CC and ITO contexts.

\section{Findings}

The coding of 88 empirical articles on IT sourcing decisions resulted in 625 relationships between the independent and dependent variables, of which 542 have a direct influence and 83 have an indirect influence (e.g., second-order constructs or moderators) on IT sourcing decisions. Of the 542 relationships related to sourcing decisions, 272 were coded for the CC model, and 270 were coded for the ITO model. We aggregated the independent variables for all studies into a set of 111 independent master variables (see Appendix $\mathrm{E}$ for the definitions). The entire coding scheme is available from the authors upon request.

Appendix D lists the set of 111 master variables and the 542 aggregated relationships between the master variables and sourcing decisions. Appendix D provides details on the most frequently studied variables in the CC and ITO contexts as well as results from empirical examinations of the relationships between the independent variables and IT sourcing decisions. The findings are briefly discussed below.

\section{Asset characteristics}

We denote the asset as an object of the sourcing decision, that is, the object being outsourced. Asset characteristics are specific to the type of asset that is considered for sourcing from an external service provider, such as the strategic importance of the application being outsourced. Independent variables that examine the influence of asset characteristics on sourcing decisions are the most frequently studied among the seven categories. This category contains 17 independent variables that have been examined 140 times. Cost savings is the most commonly studied determinant (51 times: 22 times for cost savings in general, 20 times for production costs, and 9 times for transaction costs), followed by asset specificity ( 37 times: 15 times for technical specificity, 11 times for site specificity, and 11 times for human asset specificity), and the strategic importance of the asset (13 times).

The results for only two variables (cost savings and the strategic importance of the asset) are consistent for both CC and ITO (i.e., the same findings at least $60 \%$ of the time and at least five examinations for both CC and ITO). The results for the two variables measurement problems and technical complexity are consistent for ITO only, as research on this variable in the CC context is lacking. Further, the results for cost uncertainties are consistent in the overall sample, but research on this variable is lacking in both subsamples (investigated fewer than five times in each subsample). Finally, the results for asset specificity are consistent for CC but inconsistent for ITO.

\section{Solution characteristics}

Solution characteristics denote characteristics that are specific to a concrete solution (i.e., a cloud service), such as functional characteristics or contract specifics. The solution characteristics category consists of seven independent variables whose influence on sourcing decisions has been examined only eight times. Consequently, because of a lack of empirical evidence, none of the variables meets our inclusion criteria. The only independent variable whose influence on sourcing decisions was studied twice is perceived contract clarity, and both studies report a positive, significant relationship between perceived contract clarity and sourcing decisions (Pinnington and Woolcock, 1995; Currie et al., 2004).

\section{Technology characteristics}

Technology characteristics include determinant factors that are inherent to the particular sourcing option (i.e., CC or ITO), such as the risk of losing access to data and the benefits of increased scalability. Researchers have investigated a rich array of technology characteristics as determinant factors of IT sourcing decisions, predominantly concerning the risks or benefits of the desired sourcing option. In all, the relationship between technology characteristics and sourcing decisions has been examined 128 times. Technology characteristics include 19 independent variables, nine of which are specific benefits and four of which are specific risks of the examined sourcing option. Some studies aggregate several risks or benefits within one generic risk/benefit construct (e.g., Daylami et al., 2005), others investigate how specific risks/benefits influence sourcing decisions (e.g., Saya et al., 2010), and others employ a two-stage model (e.g., Benlian and Hess, 2011). Some technology characteristics are conceptualized as benefits (e.g., better security (Gupta et al., 2013) or increased availability (Currie et al., 2004)) as well as risks (e.g., availability risks (Lechesa et al., 2011) or security risks (Wu et al., 2011)). The most frequently examined benefits are access to specialized resources (20 times), a focus on core competencies (17 times), and flexibility (16 times). The most frequently examined risks are security concerns (15 times), loss of control (eight times), and availability concerns (five times).

The results for only two independent variables are consistent for CC and ITO decisions (access to specialized resources and flexibility gains). The result for security risks, availability risks, reduced time to market, and perceived complexity are consistent for CC, but research on these variables in the ITO context is lacking. Focus on core competencies and quality improvements have consistent results in the ITO context; however, research on these variables in the CC context is lacking. The results for risk of losing control are consistent in the overall sample, but research on this variable is lacking in both subsamples.

\section{Client firm characteristics}

With 24 independent variables, the client characteristics category contains the most variables among the seven categories. Researchers have examined the influence of client characteristics on sourcing decisions 127 times. Client size is the most frequently discussed variable in this category (26 times). Furthermore, researchers have investigated determinant factors such as internal IT capabilities (22 times) and industry (10 times). Only the results for industry are 
consistent results with both models. The results for top management support are consistent for ITO only, as findings on this variable in the CC context are scarce. Further, the results for internal IT capabilities are consistent for ITO but inconsistent for CC, and the results for client size are inconsistent with both models. The results for strategic vulnerability are consistent in the overall sample, but research on this variable is lacking in both subsamples.

\section{Individual characteristics}

Findings on the individual level are scarce, as most articles adopt a firm-level perspective. This category contains 13 variables, which researchers examined 22 times in relation to sourcing decisions. Only the influence of a decision maker's attitude toward outsourcing has been examined more than five times, and the results are consistent in the overall sample, but research on this variable is lacking in both subsamples.

\section{Environmental characteristics}

Overall, the 23 variables within the category of environmental characteristics have been examined 86 times. In our sample, uncertainty (24 times: 17 times for environmental uncertainty and seven times for behavioral uncertainty), market maturity (16 times), and institutional influences (24 times: 14 times for mimetic pressures, six times for coercive pressures, three times for normative pressures, and one time for an aggregated construct) are the most commonly examined independent variables. Market maturity is the only independent variable with consistent results across both models. The results for uncertainty are inconsistent for both CC and ITO, while the results for institutional influences are consistent for ITO but nonsignificant for CC.

\section{Vendor firm characteristics}

Vendor characteristics include eight variables that have been examined 31 times in total. Vendor service capability (14 times), support (four times), and trustworthiness (three times) are the most commonly examined independent variables in this category. Service capability is the only independent variable that has been examined more than five times, and the results are consistent for CC, although research on this variable in the ITO context is lacking.

\section{Intermediate summary of findings}

A comparison of findings from the ITO literature with findings from the CC literature, as summarized in the preceding section, revealed three types of determinant factors: (i) factors with consistent empirical evidence regarding their influence on cloud-sourcing decisions; (ii) factors with consistent empirical evidence regarding their influence on IT sourcing decisions but only limited evidence for the CC context (examined fewer than five times in the CC context); and (iii) factors with inconclusive empirical evidence in the CC and ITO contexts. For the first type of factors, the empirical results are consistent in the CC literature and are lacking in the ITO literature or are consistent in both the ITO literature and the CC literature. For the second type of factors, consistent empirical results have not yet been reported in the CC literature, but they show promise as determinant factors of cloud-sourcing decisions because the results for these factors are consistent in the overall sample and/or in the ITO sample. The third type of factors requires further discussion because the results for the two subsamples are inconclusive. Since the results for factors of type (i) and (ii) are already consistent in the literature (for either CC or ITO or for both), we do not further discuss these factors. We include these factors in our suggestions for further research, as researchers have already provided strong empirical evidence for their influence on IT sourcing decisions. Figure 1 depicts the derived factors of type (i) and (ii). To identify the most robust findings, we adapt a tiered legend from Lacity et al. (2010), which is based on the proportion of consistent findings in the overall sample. We use the symbol ' ++ ' if more than $80 \%$ of the evidence shows a positive and significant relationship between the independent variable and the dependent variable (IT sourcing decision). We use the symbol ' $t$ ' if $60 \%-80 \%$ of the evidence is

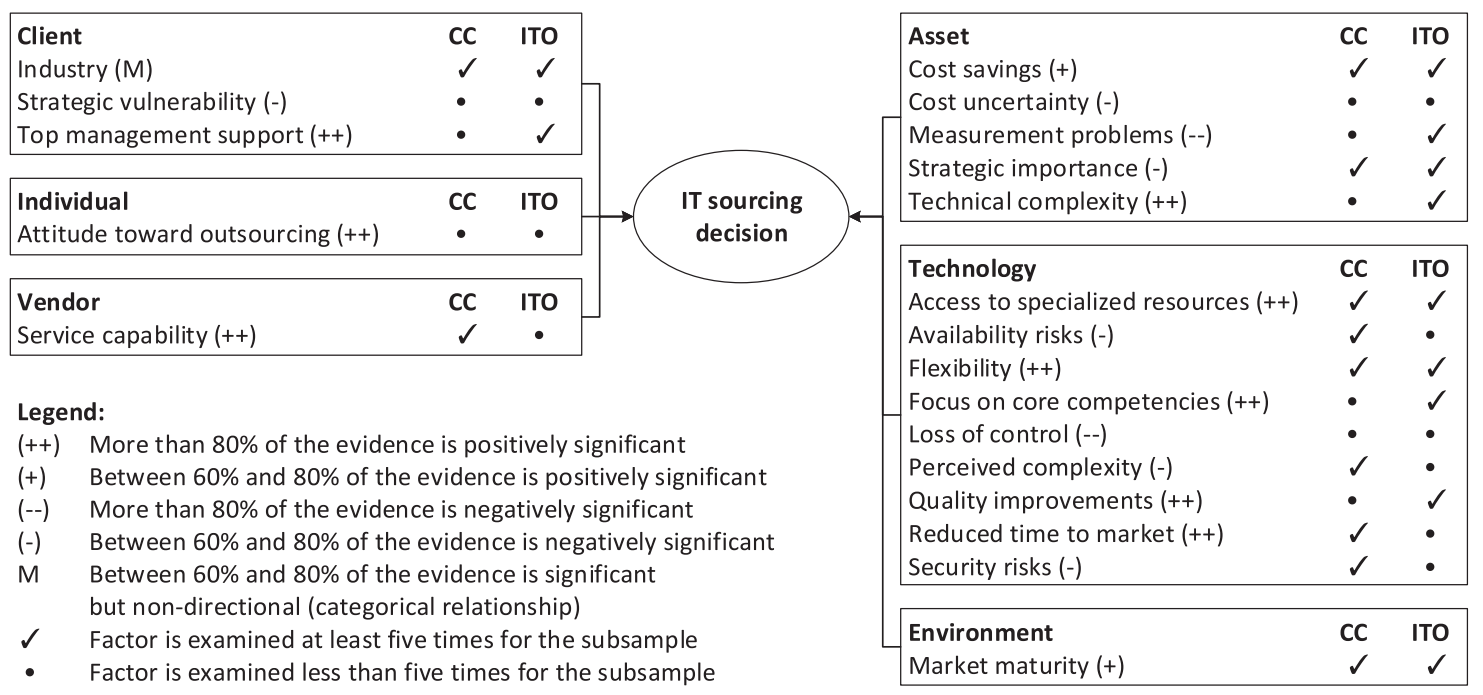

Figure 1 Determinant factors with consistent empirical evidence regarding the influence on IT sourcing decisions. 
significantly positive. Likewise, we use '--' for relationships that are shown to be significantly negative more than $80 \%$ of the time and '-' if $60 \%-80 \%$ of the evidence is significantly negative. The symbol ' $\checkmark$ ' indicates for each subsample (CC, ITO) whether a factor is examined at least five times with consistent evidence, while the symbol ' $\bullet$ ' indicates that the factor lacks examinations for the subsample (less than five times examined).

To fulfill the objective of this article and to maintain a concise and meaningful discussion, the next section focuses on the puzzling differences and inconclusive findings in the determinant factors of sourcing decisions between CC and ITO. Table 3 summarizes the factors with inconclusive results.

\section{Discussion of findings}

In this section, we discuss the factors with inconclusive and contradicting results in the CC and ITO contexts. We therefore use the arguments in Table 1 (see background section) to examine whether the inconclusive findings can be explained by peculiarities in the CC sourcing model. We discuss each factor according to the following structure. First, we summarize the main results of the articles that examined each factor. We then discuss why there may be inconsistencies between the CC and ITO contexts and offer recommendations for future research based on our discussion. Table 4 summarizes the factors that we discuss in this section, the arguments regarding which peculiarities of CC (see Table 1) could explain the identified inconsistencies, and the factors that might induce context-specific results because of interaction effects with other factors.

\section{Asset characteristics}

Asset specificity is used in reference to three major categories of assets: site specificity, physical asset specificity (also referred to as technical specificity), and human asset specificity (Williamson, 1981).

Site specificity is examined 11 times in total, including eight times for CC and three times for ITO. Except for one occurrence for CC (Loebbecke and Huyskens, 2006), all findings show a significant, negative influence of this factor on sourcing decisions (91\%) (e.g., Dibbern et al., 2003). Hence, the findings are consistently negative for CC and for the overall sample, but there is a lack of evidence regarding this factor in the ITO context.

The increased network dependence of CC increases the risks that affect site specificity, such as the risk of service breakdowns because of possible network outages, which may result in a temporary loss of access to data. Hence, site specificity requires particular consideration for assets that

Table 3 Determinant factors with inconclusive empirical evidence regarding the influence on ITO decisions and the influence on cloud-sourcing decisions

\begin{tabular}{lcc}
\hline Determinant factor & Cloud computing & IT outsourcing \\
\hline Asset specificity & - & Inconsistent \\
Client firm internal IT & Inconsistent & -- \\
capabilities & & \\
Client firm size & Inconsistent & Inconsistent \\
Uncertainty & Inconsistent & Inconsistent \\
Institutional influences & Nonsignificant & + \\
\hline
\end{tabular}

are required on a daily basis (e.g., a customer relationship management system). Furthermore, resource pooling increases the risk of information leakage (Brender and Markov, 2013) resulting from malicious behavior in shared environments (Subashini and Kavitha, 2011). In this context, site specificity concerns not just specific resources that are only available onsite (e.g., geographical location of an investment) but also restrictions on the data that are stored and processed within the asset (Rieger et al., 2013). Hence, site specificity requires particular consideration for assets that store sensitive data or that are liable to specific regulatory requirements (e.g., accounting systems). Site specificity may also be moderated by differences between service models, for instance, an asset that bears a strong competitive advantage, such as an advanced algorithm or a newly developed method (e.g., 'Summly' (Lessin, 2013)). A company may not want to outsource software development to an external contractor because knowledge could be leaked (high site specificity). However, running the algorithm in compiled code with external IaaS or PaaS solutions to increase the scalability of its use could be a valid sourcing option. By contrast, if a strategic advantage does not evolve from the asset to be outsourced (e.g., an application) but rather emerges from the data that are stored within the application (e.g., highly detailed consumer data that are stored in a market researcher's database), then cloud sourcing may not be a feasible option. Companies that rely on their unique data cannot allow such data to leak. However, outsourcing the software development of the application that grants access to their database may be an acceptable solution for such companies.

As discussed above, several indicators facilitate the need for context-specific considerations of site specificity as a determinant of cloud-sourcing decisions. In particular, we emphasize the need to distinguish the influence of site specificity according to the type of asset that is outsourced and the service model that is under consideration.

The relationship between technical specificity and sourcing decisions is examined 15 times in the examined articles, including 10 times in the CC context and five times in the ITO context. For ITO, the results for technical specificity are inconsistent (a significantly negative influence two of five times (40\%) (Aubert et al., 1996; Wholey et al., 2001) and a significantly positive influence one of five times (20\%) (Aubert et al., 2004). For CC, six of the ten studies $(60 \%)$ are consistent and report a significant, negative influence (e.g., Watjatrakul, 2005). However, $20 \%$ (two of ten times) report a significant, positive relationship (Diana, 2009; Asatiani et al., 2014), which is contrary to the predictions of TCE, and an additional $20 \%$ report no significant relationship (Loebbecke and Huyskens, 2006; Benlian et al., 2009).

Loebbecke and Huyskens (2006) argue that technical specificity may nevertheless generate transaction costs when applications are run remotely, but these increased transaction costs do not exceed cost savings arising from economies of scale. Thus, these cost savings may simply outweigh issues related to technical specificity. Furthermore, the influence of technical specificity is expected to vary with company size (Benlian, 2009; Asatiani et al., 2014). For instance, Benlian et al. (2009) find that technical specificity has the strongest effect on large enterprises because large enterprises tend to have complex, highly specific business processes in place that are supported by fragmented IT infrastructures with legacy systems and 
Table 4 Summary of discussion of inconclusive findings, the peculiarities of CC that might explain the inconclusive findings, and recommendations for future research

\begin{tabular}{|c|c|c|}
\hline Determinant factor & $\begin{array}{l}\text { Peculiarities of cloud computing that might } \\
\text { explain inconclusive findings }\end{array}$ & $\begin{array}{l}\text { Factors to consider in future research that might } \\
\text { yield context-specific results }\end{array}$ \\
\hline \multicolumn{3}{|l|}{ Asset specificity } \\
\hline Technical specificity & $\begin{array}{l}\text { - Scope: standardized services } \\
\text { - Governance mode: different service } \\
\text { models }\end{array}$ & $\begin{array}{l}\text { - Company size } \\
\text { - Service model under consideration (SaaS vs } \\
\text { IaaS/PaaS) } \\
\text { - Type of asset to be outsourced (strategic } \\
\text { importance) } \\
\text { - Environmental uncertainty }\end{array}$ \\
\hline $\begin{array}{l}\text { Client - firm internal IT } \\
\text { capabilities }\end{array}$ & $\begin{array}{l}\text { - Governance mode: different service } \\
\text { models } \\
\text { - Scope: role of the IT department as } \\
\text { service integrator }\end{array}$ & $\begin{array}{l}\text { - Service model under consideration: lack of } \\
\text { internal IT capabilities as driver for SaaS and } \\
\text { inhibitor for IaaS/PaaS } \\
\text { - Recent recruiting of IT personnel }\end{array}$ \\
\hline Client firm size & $\begin{array}{l}\text { - Decision process: self-service } \\
\text { procurement }\end{array}$ & $\begin{array}{l}\text { - Type of asset to be outsourced (green field or } \\
\text { replacement of existing system) }\end{array}$ \\
\hline \multicolumn{3}{|l|}{ Institutional influences } \\
\hline Coercive pressures & $\begin{array}{l}\text { - Environment: uncertain legal } \\
\text { conditions }\end{array}$ & $\begin{array}{l}\text { - Industry } \\
\text { - Type of asset to be outsourced (site specificity) }\end{array}$ \\
\hline Mimetic pressures & $\begin{array}{l}\text { - Environment: volatile and immature } \\
\text { market }\end{array}$ & \\
\hline Normative pressures & $\begin{array}{l}\text { - Environment: Standardization } \\
\text { movement } \\
\text { - Governance mode: community cloud as } \\
\text { deployment model }\end{array}$ & \\
\hline
\end{tabular}

heterogeneous applications. Thus, the role of technical specificity may vary with company size when applications or infrastructure components are outsourced.

Increasing standardization efforts in the field of CC (Bernnat et al., 2012), open interfaces, interoperability, and custom-built mash-ups of cloud services enable customers to build highly specific solutions that may reduce the negative influence of technical specificity in the CC context. The market for SaaS is growing, and external business applications are increasingly provided externally (Winkler and Brown, 2013). Organizations are able to use cloud services even for complex enterprise software, such as enterprise resource planning or customer relationship management. Diana (2009) argue that highly complex IT environments may present more opportunities for outsourcing arrangements (e.g., outsourcing single, highly specific applications to an 
external cloud service provider). However, SaaS solutions are limited in terms of their customizability, which limits the uniqueness of assets that are sourced via CC. Therefore, assets with low technical specificity might be more suitable for SaaSbased sourcing (Benlian et al., 2009). Highly technically specific assets that exceed the configuration and customization limits of SaaS solutions may nevertheless be candidates for outsourcing the underlying infrastructure or platform of assets to IaaS or PaaS solutions.

As Lacity et al. (2011) note, the main constructs of TCE were developed in the 1930s and were tested and validated in product-sourcing contexts such as coal, petroleum coke, and natural gas markets. Considering the inconsistencies found in their review, the authors ask whether 'theories based on evidence from sourcing products [can] be appropriate for studying ITO services' (Lacity et al., 2011: 145). For IT sourcing, TCE constructs have been used in product purchasing, such as software acquisition or software development outsourcing (Tiwana and Bush, 2007), as well as in service sourcing, such as BPO (Tanriverdi et al., 2007) or CC (Benlian et al., 2009). The inconclusive findings regarding the influence of technical specificity on sourcing decisions in the ITO context have been extensively discussed in recent literature reviews (Alaghehband et al., 2011; Lacity et al., 2011). Because we found consistent empirical support for technical specificity in the context of CC, we recommend that further research examine technical specificity in cloud-sourcing decisions. In particular, differences in service models and differences according to company size may be eminent, as discussed above.

Human asset specificity yields inconsistent results. In total, the relationship between human asset specificity and sourcing decisions is studied 11 times: 2 times in the context of CC and nine times in the context of ITO. In both instances (100\%) in the CC context, the relationships are nonsignificant (Loebbecke and Huyskens, 2006; Schwarz et al., 2009). In the ITO context, a significant, negative relationship is reported five of nine times (56\%) (e.g., Jain and Thietart, 2013), and a nonsignificant relationship is reported four times (44\%) (e.g., Dibbern and Heinzl, 2009).

Considering CC as 'infinite computing resources available on demand, quickly enough to follow load surges' (Armbrust et al., 2010: 50), we argue that IaaS and PaaS solutions may be particularly suitable for assets with high levels of technical complexity and human asset specificity. IaaS and PaaS enable organizations to outsource technically complex tasks (e.g., managing infrastructures of assets with extensive availability and security requirements and uncertain load surges) to an external vendor while ensuring that tasks requiring integrative knowledge of the business, processes, and environment of an organization remain in-house (e.g., highly customized software that supports core business processes and that yields a competitive advantage). This argument is supported by the findings of Aubert et al. (2012), who report that organizations are more likely to outsource if the degree of technical skills required is high (high technical complexity) and are less likely to outsource if the degree of business-related skills is high (high human asset specificity). In this vein, assets with high technical complexity and low human asset specificity may be more suitable for SaaS solutions because with decreasing human asset specificity, the tasks to execute can be served by standardized software services with open APIs to connect to more specific business functions or assets within an organization.

Only two studies have examined human asset specificity as a determinant of cloud-sourcing decisions; thus, we lack empirical evidence to further assess our argument in this discussion. Hence, we recommend further empirical research on the interaction effects of technical complexity and human asset specificity for IaaS/PaaS and SaaS solutions.

\section{Client firm characteristics}

Results regarding the influence of a client firm's internal IT capabilities on sourcing decisions differ between the CC (inconsistent influence) and ITO (consistent negative influence) contexts. The relationship between a client's internal IT capabilities and sourcing decisions is studied 22 times in the examined articles, with 14 articles concerning CC and eight articles concerning ITO. For CC, four of the 14 (29\%) articles report a significant, negative relationship between internal IT capabilities and cloud-sourcing decisions (e.g., Kern et al., 2002), and six of the $14(43 \%)$ articles report a significant, positive relationship (e.g., Lian et al., 2014). Of the eight investigations in the ITO context, seven (88\%) report a significant, negative relationship (e.g., Kern et al., 2002).

Schwarz et al. (2009: 771) argue that limited support for internal IT capabilities is observed because there is 'an abundant supply of IT personnel with adequate technical expertise'; thus, gaps in internal IT capabilities can be easily filled. Kern et al. (2002) argue that companies outsource their IT activities because of a lack of trained and skilled IT personnel, whereas others argue for internal IT capabilities as a prerequisite for integrating cloud services into an organization's IT landscape (e.g., Currie et al., 2004; Lian et al., 2014). However, IT capabilities are specific to the service model that is used.

For IaaS or PaaS, which require cloud-specific knowledge of software architects, internal IT capabilities are a prerequisite for adopting IaaS or PaaS services; thus, a lack of IT capabilities would inhibit cloud sourcing. For SaaS, the lack of internal IT capabilities might be a driver if software applications cannot be developed, maintained, and operated in-house (e.g., Morabito, 2003).

A lack of internal IT capabilities can be addressed either by gaining competencies (e.g., hiring experts, training existing personnel) or by delegating IT tasks to external providers (i.e., outsourcing). Thus, the desire to hire IT personnel may be an indication of a lack of IT capabilities. Qu and Pinsonneauli (2011) find that companies that have hired or attempted to hire staff with special IT skills in the recent past are more likely to outsource IT; the authors do not distinguish between successful and unsuccessful recruiting. In the context of ITO, unsuccessful recruiting may drive outsourcing because training personnel is the only alternative, which might not be suitable if, for instance, time pressure exists. However, in the context of CC, particularly IaaS and PaaS, unsuccessful recruiting may instead inhibit the adoption of infrastructure or platform services because the necessary skills to leverage cloud benefits and to deploy cloud application may be lacking.

We recommend that further research differentiate between successful and unsuccessful recruiting activities as indicators 
of a lack of IT capabilities and account for IT capabilities as a driver or inhibitor depending on the service model under consideration. We argue that the contradictory findings regarding IT capabilities in the CC context can be ascribed to the new role of the IT department as a service integrator and the novel capabilities that are required (Ragowsky et al., 2014) as well as to the capabilities required for different service models.

The size of the client organization is measured in various ways, such as in terms of employees (e.g., Guenther and Tamm, 2002), market capitalization (e.g., Hall and Liedtka, 2005), total assets (e.g., Loh and Venkatraman, 1992a), total sales (e.g., Nam et al., 1996), or a combination of these measures. The influence of a client's company size on sourcing decisions is frequently discussed in the literature, but inconsistent results are reported. In our sample, client size is studied 26 times, including 14 articles considering CC and 12 articles considering ITO. For CC, two of the 14 (14\%) articles report a significantly positive relationship (Diana, 2009; Low et al., 2011), three (21\%) report a significantly negative relationship (e.g., Guenther and Tamm, 2002), and three (21\%) provide evidence of a non-directional relationship (e.g., Yao et al., 2010). For ITO, five of the $12(42 \%)$ articles report a significantly positive relationship (e.g., Hall and Liedtka, 2005 ), and one article (8\%) provides evidence of a nondirectional relationship (Gonzalez et al., 2005b).

Although the findings of CC and ITO studies may be inconsistent, CC studies tend to find a negative relationship, whereas ITO research tends to find a positive relationship. However, such an argument must be used with caution given that organization size is not a significant determinant in nearly half of the reported results (46\%). Ang and Straub (1998), who find a significant, positive relationship between client size and sourcing decision, argue that small organizations have greater difficulty generating economies of scale in their IT operations that allows them to justify internal operations. Arguments for client size not being a significant determinant include that the findings are 'generally robust and valid across firms differing in sizes' (Loh and Venkatraman, 1992a: 20) and that 'SaaSbased outsourcing is not only targeted at SMBs [small and medium-sized businesses], but also a valid sourcing option for larger corporations' (Benlian et al., 2009: 367). The three studies that report a negative relationship between client size and sourcing decisions are those concerning software services, and these studies argue that there might be 'external factors at work [e.g., economical or psychological] that cause smaller companies to be more open towards the ASP approach' (Guenther and Tamm, 2002: 1545). Consistent with this argument, Kern et al. (2002: 171) propose that 'small and medium sized companies are especially interested in ASPs because they can get access to strategic resources which are often prohibitively costly yet essential [...] to remain resource competitive against large enterprises'. According to the findings of Benlian (2009), client size has a significantly negative association with SaaS-based sourcing within subgroups of SMBs and large enterprises but has no associate across groups. However, their findings also indicate that that SMBs tend to take greater advantage of flexible software sourcing models than large corporations but that they have narrowing future adoption rates (Benlian, 2009). These findings are similar to the findings of Yao et al. (2010), who observe a U-shaped relationship between client size and sourcing decisions, meaning that small companies and large companies tend to have greater intention to adopt ASP than medium-sized companies. A similar U-shaped relationship is confirmed by Berg and Stylianou (2009).

Small or medium-sized enterprises (SMEs) in particular must interact with cloud-service providers in a self-service manner and must gather information themselves (Wollersheim et al., 2013). With CC, task responsibilities shift between the provider and customer (Susarla et al., 2010). The provider is responsible for activities such as the provision and maintenance of underlying infrastructure and software applications. However, responsibilities for verifying requirements can shift from providers to customers. Additionally, CC allows business divisions to procure IT services by themselves. There is no need for administrator privileges to install local applications on end users' devices if cloud services are accessible via a Web browser. Cloud services encapsulating functionality tailored to single divisions typically incur expenses within the monthly underwriting limits of division managers without the need for approval from higher levels of the organizational hierarchy (so-called 'shadow IT'). These factors encourage business divisions to procure dedicated cloud services autonomously. Consequently, the sourcing process, as well as the constitution of the procurement team, in CC differs from traditional sourcing processes that include requests for information or requests for proposals. Such a self-service evaluation accompanies the use of trial cloud services and a process of reflecting on user-generated content such as blogs and forums. In other research contexts, user-generated content has proved to be particularly influential on decision making during the initial screening stage (Aggarwal and Singh, 2013). Therefore, SMEs may have different decision outcomes depending on factors such as adapted procurement processes or different constellations, roles, and division of labor within the procurement team (Kans, 2012; Fulk, 1993).

Furthermore, we want to stress that research on sourcing decisions concerning 'green field' $v s$ 'switching' is lacking. For instance, startups or SMEs that do not have specific applications in use (e.g., a project management software) or large organizations launching a new software product may consider different factors than an organization migrating an existing product to the cloud (Serva et al., 2003).

Reflecting on the above-discussed findings, we argue that company size plays a role in cloud-sourcing decisions and recommend that further research examine this determinant factor, particularly given the self-service procurement of CC and the differences that might occur when replacing an existing system or adopting a new system.

\section{Environmental characteristics}

Uncertainty refers to the degree of unpredictability, complexity, and imperfect information that is inherent to a transaction. Two types of uncertainty exist: behavioral uncertainty and environmental uncertainty (Williamson, 1985).

In total, the relationship between environmental uncertainty and sourcing decisions is studied 17 times, including nine times in the CC context (inconsistent findings) and eight times in the ITO context (inconsistent findings). For CC, the relationships are significantly positive three of nine times (33\%) (e.g., Asatiani et al., 2014), whereas the relationships are significantly negative five of nine times (56\%) (e.g., Benlian, 2009). 
In the ITO context, the relationships are significantly positive three of eight times (38\%) (e.g., McLellan et al., 1995), whereas the relationships are significantly negative four of eight times (50\%) (e.g., Nam et al., 1996).

Environmental uncertainty is conceptualized in terms of technological uncertainty (e.g., Ang and Cummings, 1997), demand uncertainty (e.g., Aubert et al., 2012), requirement uncertainty (Apte et al., 1997), product uncertainty (Asatiani et al., 2014), or overall uncertainty in the external environment (e.g., Nam et al., 1996). When examining the various conceptualizations of environmental uncertainty separately (e.g., technological uncertainty $v s$ product uncertainty), the results are inconclusive as well, predominantly because of the lack of studies using each conceptualization.

To understand the inconsistent findings in the CC context, we consider the diverging conceptualizations of environmental uncertainty and distinguish demand uncertainty (uncertainty in the volume of resources that will be required) and product uncertainty (difficulties in evaluating the capabilities of different cloud services because of information asymmetries). The on-demand pricing model of CC bears the risk of unpredicted costs or economic denial of service attacks (Brender and Markov, 2013). However, flat-rate pricing models or pricing models based on the number of registered users do not carry such risks (Koehler et al., 2010). Furthermore, under- or overutilization of resources can be compensated by a flexible contractual mode and can outweigh cost unpredictability (Saya et al., 2010). Thus, we argue that a high level of demand uncertainty positively affects cloud sourcing. In contrast, a high level of product uncertainty owing to information asymmetries may negatively affect cloud sourcing. SMEs in particular demand decision support through contractual or reputational mechanisms to mitigate such uncertainties (Benlian, 2009), for instance, certifications of cloud services (Lansing et al., 2013; Sunyaev and Schneider, 2013).

Considering the inconsistent findings for environmental uncertainty and reflecting on these findings with respect to the specific characteristics of CC (i.e., measured, on-demand selfservice over a network), we argue that environmental uncertainty requires further consideration as a determinant of cloud-sourcing decisions, and we specifically differentiate between demand uncertainty as a driving factor and product uncertainty as an inhibiting factor.

Behavioral uncertainty is examined seven times: two times for CC and five times for ITO. Both studies in the CC context report a nonsignificant influence of behavioral uncertainty on sourcing decisions (Serva et al., 2003; Watjatrakul, 2005), whereas three of five $(60 \%)$ of the studies in the ITO context are consistent and report significantly negative relationships (e.g., Dibbern et al., 2003).

Opportunism is a threat only for markets with a small number of vendors (Williamson, 1975). The contractual mode of cloud services with short-term contracts enables clients to switch between providers for standardized, commodity-type services at a low cost, thereby increasing the client's willingness to switch vendors if the client is not satisfied with the outsourcing arrangement (Whitten et al., 2010). However, low-cost switching applies only to standardized services (e.g., low technical specificity) with many available provider options. Highly specialized services, which are difficult to replace and lack open interfaces, might be more difficult to source via CC. Thus, the type of asset and the interference of other factors may play a role in the influence of behavioral uncertainty on sourcing decisions. For instance, a highly mature cloud market with a high density of reputable providers may decrease the potential for opportunistic behavior (Asatiani et al., 2014). Further research is required to establish the validity of this argument.

Behavioral uncertainty induces the need to increase investments in monitoring and enforcement (Watjatrakul, 2005). The usage-based pricing models and intangibility of cloud services increase the complexity of performance measurement for clients because clients lose control over the asset and must cope with the tools and information that the vendor provides. However, sophisticated monitoring tools that providers need to establish to measure their services for billing purposes can be provided to clients as self-service reporting and monitoring tools. Hence, clients are able to thoroughly monitor services, which would not be possible with in-house service provision. Increased ease of monitoring does not necessarily decrease the risk of opportunistic behavior (Alaghehband et al., 2011), but may moderate the negative influence of behavioral uncertainty on sourcing decisions.

Research has also shown that uncertainty (behavioral and environmental) interacts with other determinant factors. For instance, Watjatrakul (2005) investigate the interference of strategic importance, asset specificity, and uncertainty. Their findings indicate that nonstrategic resources are not necessarily candidates for outsourcing; however, the interaction of the three factors plays an important role in sourcing decisions. These authors present evidence that in a highly uncertain environment, nonstrategic resources with both low and high levels of specificity are maintained in-house; by contrast, in an environment with low behavioral uncertainty, resources that are highly specific and nonstrategic are maintained in-house. Thus, organizations tend to use their specific knowledge to control for uncertainties on an internal level. These findings are consistent with the findings of Jain and Thietart (2013), who report that the risk of the expropriation of valuable (high strategic importance) firm-specific (high human asset specificity) knowledge resulting from the opportunistic behavior of vendors has a negative influence on sourcing decisions. Benlian et al. (2009) find that strategic importance is significant only for CRM and ERP applications but not for office applications, which are evaluated with low environmental uncertainty, technical specificity, strategic importance, and inimitability.

The discussion above suggests that uncertainty has interaction effects with other determinant factors from strategic, economic, or social theories, which could explain the inconsistent findings in the CC and ITO literature (Jayatilaka et al., 2003; Watjatrakul, 2005; Benlian et al., 2009; Schwarz et al., 2009). We emphasize the need to further explore the interaction effects with the flexible contractual mode of CC and the maturity of the cloud market (e.g., available providers for specific assets).

Institutional influences refer to the pressures for organizations to adjust their behaviors to conform to shared notions that may manifest as coercive (e.g., laws, regulations, or sanctions), mimetic (e.g., mimicking the behaviors of competitors, experts, or market leaders), and normative (e.g., norms, best practices, or compliance requirements) pressures (DiMaggio and Powell, 1983). 
Coercive pressures are studied six times in the examined articles, four of which are in the CC context (only one time (25\%) with a significantly negative influence) and two of which are in the ITO context (both finding a significantly negative influence).

The CC environment is characterized by uncertainty and a lack of transparency that inhibits adoption, as well as an immature legal situation, as indicated by legal conflicts between the United States and Europe in data protection principles (Boehler and Ramos, 2014) or the latest information revealed about the NSA PRISM program (Cloud Security Alliance, 2013). Six studies investigate coercive pressures. The three studies that show a significant, negative influence are all in industries with strong governmental regulation, such as financial services (Ang and Cummings, 1997; Rieger et al., 2013) and health care (Wholey et al., 2001). Lian et al. (2014) investigate coercive pressures in the health-care sector (Taiwan hospitals) and find no significant influence. The authors argue that the Taiwan government has implemented an electronic medical record policy that is a driver of CC adoption rather than an inhibiting factor. The other studies showing a nonsignificant influence of coercive pressures focus on multiple industries (Borgman et al., 2013; Kung et al., 2013).

Hence, we argue that industry-specific effects may lead to inconsistent results regarding coercive pressures and that coercive pressures should be specifically examined with regard to companies' originating industry. In this context, interaction effects with the degree of site specificity of the outsourced asset (e.g., related to the type of data that are stored in the outsourced asset) may arise, and these effects should thus be considered in future research as well.

The results on the influence of mimetic pressures on sourcing decisions are inconsistent in both CC and ITO research. In total, mimetic pressures are studied 14 times, including four times in the CC context and ten times in the ITO context. The influence of mimetic pressures on cloudsourcing decisions is significantly positive in only one of four (25\%) articles (Wu et al., 2011), whereas in eight of ten (80\%) articles, the influence of mimetic pressures on ITO decisions is positive and significant (e.g., Fiedler et al., 2013).

The findings regarding the effect of mimetic pressures on cloud-sourcing decisions may be inconclusive because mimetic pressures may influence sourcing decisions indirectly rather than directly. Saya et al. (2010) report that institutional influences significantly affect perceived risks (e.g., security) and perceived benefits (e.g., accessibility) but do not directly affect cloud-sourcing decisions. Similarly, Benlian et al. (2009) find that the opinions of experts or market researchers play a major role in shaping the attitudes of top management toward cloud sourcing but that they have no direct influence on sourcing decisions. These authors argue that organizations appear 'not to blindly follow the recommendations of other organizations by unreflectively imitating their behavior. Instead, the opinions of third parties seem to inform in the IT user companies' process of building their own attitude about SaaS'. This argument is consistent with the nonsignificant results of Blaskovich and Mintchik (2010), who find a significantly positive influence of mimetic pressures on cloudsourcing decisions only when CIO skills are weak. Considering the high level of uncertainty within the CC environment, mimicking organizations that are perceived to be more legitimate or successful is a response to uncertainty (DiMaggio and Powell, 1983). Decision makers are influenced by the environment both inside and outside their organization, and both sources of influence are strong predictors of sourcing decisions (Loh and Venkatraman, 1992b; Dibbern et al., 2012). Hu et al. (1997) argue that the combined effects of external media, vendor pressure, and internal communications among managers at the personal level significantly influence sourcing decisions. More specifically, Morgan and Conboy (2013) report that customers are negatively preoccupied about the term cloud, and because of this perception, service providers avoid mentioning the term cloud per se and instead refer to a new service delivery model.

Although findings on the direct influence of mimetic pressures on cloud-sourcing decisions are scarce in the CC context, we argue that mimetic influences should be considered in further research as a determinant factor of cloudsourcing decisions, particularly with respect to other factors from social or organizational theories, as research has shown that these relationships are strong and significant in the CC context (Benlian et al., 2009; Saya et al., 2010; Wu et al., 2011).

Normative pressures are investigated only three times (including two times in the CC context). The results for CC show a positive, significant influence in one of the two studies (50\%) (Kung et al., 2013), and the single study in the ITO context (Fiedler et al., 2013) also shows a positive, significant relationship.

Because of the limited number of empirical investigations on normative pressures, we cannot draw conclusions based on our coding results. However, with the maturation of the cloud market and the establishment of cloud-dedicated industry associations, such as the Cloud Security Alliance or EuroCloud, a large number of norms and best practices for CC have been established. The International Organization for Standardization (ISO) is currently developing a code of practice for information security controls for CC in alignment with the prominent ISO 27000 series of standards (International Organization for Standardization, 2013). Furthermore, community cloud as a deployment model enables industry associations to provide members with cloud services that implement industry best practices and that are compliant with industry-specific regulations.

Increasing standardization efforts that are particularly suited to CC and the emergence of community cloud platforms for specific industries might drive organizations to consider CC adoption. We therefore suggest that future research incorporate normative pressures and challenge the argument regarding whether cloud-specific standardization movements and community cloud platforms drive cloudsourcing decisions.

\section{Implications for research}

The synthesis of the literature on determinant factors of IT sourcing decisions enables us to draw conclusions based on not only the in-depth discussion of contradicting findings between research on CC and research on ITO (Figure 1, Table 3, and Table 4) but also the emergent trends in the literature. This section discusses implications for future research based on both types of findings.

To answer our first research question, we examined what we can learn from the rich body of research on ITO to identify 
determinant factors of cloud-sourcing decisions. Overall, within the literature on ITO, researchers have provided an extensive body of research on decision making and applied various economic, strategic, organizational, and social theories (Dibbern et al., 2004; Lacity et al., 2010). However, within the literature on CC, instead of leveraging this insightful body of knowledge, researchers have focused on technological aspects and cost savings as determinant factors, as 39\% of the examined relationships between determinant factors and cloud-sourcing decisions concern these factors. The comparison of the factors identified within the ITO literature with the factors identified within the CC literature shows that a wide range of determinant factors of ITO decisions remain valid for cloud-sourcing decisions (see Figure 1). Hence, we suggest that future research in the CC context focus on factors other than technology characteristics, such as organizational, individual, and environmental characteristics.

To answer our second research question, we identified the differences between the determinant factors of ITO decisions and the determinant factors of cloud-sourcing decisions (see Table 3) and discussed how these differences might be explained (see Table 4). The results regarding the five factors asset specificity, internal IT capabilities, client size, uncertainty, and institutional influences are inconclusive between research on CC and research on ITO. Our findings concerning the differences between CC and ITO research have several implications for future research on CC.

Most of the factors with consistent results for ITO also have consistent results for CC, and most of the factors with inconsistent results for ITO also have inconsistent results for CC. There are only three exceptions: internal IT capabilities (consistent negative influence for ITO, inconsistent influence for CC), institutional influences (consistent positive influence for ITO, nonsignificant influence for CC), and asset specificity (inconsistent influence for ITO, consistent negative influence for CC). Table 4 summarizes our arguments regarding how the peculiarities of CC may alter the influence of these determinant factors on sourcing decisions in the $\mathrm{CC}$ context. For internal IT capabilities, we argue that the changing role of IT departments and differences between service models are reasons for the inconclusive findings in the CC literature. Despite the limited findings regarding institutional influences on cloud-sourcing decisions in the literature, we argue that the industry-specific findings in the literature (for coercive pressures), the indirect influence of mimetic pressures on sourcing decisions (e.g., interaction effects with constructs on the individual level), and the advancing activities of standardization bodies (for normative pressures) induce the need for further investigation of institutional influences in the context of cloud-sourcing decisions. Apart from the specific characteristics of service models for all types of asset specificity, the high level of network dependence (site specificity), the scope of standardized services (technical specificity), and the high level of scalability (human asset specificity) are reasons why asset specificity should be reconsidered in the CC context. Further research in the context of CC is necessary to challenge these arguments. Furthermore, we identified factors that are inconsistent for both CC and ITO: namely, client size and uncertainty. Regarding client size, we argue that owing to the ondemand self-service procurement of cloud services, decision processes change for SMEs. In-depth research focusing on decision processes in organizations of different company sizes is thus needed to further understand whether and how decision processes differ with company size. Regarding uncertainty, we argue that because of the peculiarities of CC (i.e., measured, on-demand self-service over a network), future research should distinguish environmental uncertainty by demand uncertainty and product uncertainty to clarify the inconsistent findings in the context of CC. The influence of behavioral uncertainty on cloud-sourcing decisions might be altered by usage-based pricing models and low switching costs for specific asset types. Based on all of the aforementioned arguments (see Table 4 for a summary), we call for further research to assess our arguments regarding the inconclusive findings in extant research.

Factors with limited evidence for CC but consistent empirical evidence for ITO or the overall sample may be promising determinant factors to consider in future CC research. Surprisingly, the factors with the strongest empirical evidence regarding their influence on ITO decisions are scarcely researched in the CC context. In the ITO context, empirical results regarding technical complexity (100\% positive influence on sourcing decision across eight studies), quality improvements (100\% positive influence on sourcing decision across ten studies), and measurement problems ( $89 \%$ negative influence on sourcing decision across nine studies) are generally consistent across studies. However, in the CC context, technical complexity (100\% positive influence on sourcing decision in only one study), quality improvements (not examined yet), and measurement problems (67\% negative influence on sourcing decision across only three studies) have scarcely been researched. In our discussion, we identify technical complexity and measurement problems as determinant factors that might interfere with asset specificity and behavioral uncertainty (see Table 4 ). These factors may prove to be strong predictors of cloud-sourcing decisions; thus, they should be considered in future research. Additionally, future CC research may examine factors with limited evidence in both subsamples but consistent empirical evidence in the overall sample as determinant factors of sourcing decisions. Such factors include the decision-maker's attitude toward outsourcing, cost uncertainty, risk of losing control, and the strategic vulnerability of the client (see Figure 1).

In summary, ITO research provides a valuable basis for future research on CC. Although certain specific factors may differ between these contexts, future research on CC should similarly consider integrated theoretical perspectives (e.g., Benlian et al., 2009; Kung et al., 2013; Asatiani et al., 2014; Lian et al., 2014) instead of focusing on technological factors. When comparing the determinant factors of CC and the determinant factors of ITO, we also identified factors that provide consistent empirical evidence for CC but that are scarcely considered in ITO research. However, in line with the argument above, these factors predominantly concern technological aspects: security risks, availability risks, perceived complexity of the innovation, reduced time to market, and vendor's service capabilities. Thus, future research on ITO might consider these factors. In particular, the lack of research on vendor capabilities has already been identified in the review of Lacity et al. (2010).

As our discussion highlights, determinant factors may diverge according to the cloud service model. The three service models of CC share common characteristics (e.g., networkbased access, measured service, self-service provisioning) that 
result in common challenges (e.g., internet connectivity, monitoring and pricing, resource management) and similar factors driving sourcing decisions. However, given our discussion (e.g., regarding the service model-specific considerations of asset specificity or the internal IT capabilities of the client firm) and empirical evidence related to outsourcing different types of IS functions (Lacity and Hirschheim, 1993a; Benlian et al., 2009; Dibbern and Heinzl, 2009), the determinant factors of decisions to source SaaS solutions may considerably differ from the determinant factors of decisions to source IaaS or PaaS solutions. Although research on IaaS and PaaS is evolving (e.g., Giessmann and Stanoevska, 2012; Repschlaeger et al., 2012), research on the determinant factors of sourcing decisions related to these service models and the differences between the service models is currently lacking. We therefore call for further research on specific cloud service models, particularly research on IaaS and PaaS adoption and comparative research on the service models.

Additionally, we encourage further research to provide inter-group comparisons, as extant research has already revealed various differences between investigated groups, such as adopters vs non-adopters (Benlian and Hess, 2011; Borgman et al., 2013; Lian et al., 2014), and differences among countries (Apte et al., 1997), industry sectors (Hancox and Hackney, 2000; Currie et al., 2004), and outsourced functions (Benlian et al., 2009; Dibbern and Heinzl, 2009). For instance, Benlian and Hess (2011) find noteworthy differences between the influences of benefits and risks for adopters vs nonadopters of SaaS. IT executives in non-adopter firms expect SaaS to improve the quality of their services and to enable a focus on core competencies, but these factors fail to drive SaaS adoption at adopter firms. In addition to identifying these differences, future research should provide evidence for the underlying mechanisms driving differences, for instance, between adopter and non-adopter firms.

Drawing from the entire set of 88 articles, we find that researchers have applied various theories to examine IT sourcing decisions. Overall, TCE (32 times) and the resourcebased view of the firm (16 times) are the most frequently used theories. The majority of research applies macro-perspective theories, for both CC and ITO. Macro-perspective theories consider factors from the standpoint of an entire organization, whereas a micro-level perspective concerns an individual decision makers' standpoint (Vetter et al., 2011). In all, 80 articles apply a macro-perspective (e.g., Yao et al., 2010), only five articles investigate determinant factors on the micro level (e.g., Li et al., 2006), and only three adopt a mixed perspective (Dibbern et al., 2003; Benlian et al., 2009; Lian et al., 2014). Researchers applying multiple perspectives or integrating micro- and macro-level theories emphasize the strong explanatory power of behavioral theories and demand further combinations of theories from various fields, such as economics and psychology. We therefore emphasize the need for further research applying a micro-level perspective to investigate cloud-sourcing decisions. We suggest that future research combine factors from strategic and economic theories with factors from social or organizational theories, particularly determinant factors from the categories individual characteristics and environmental characteristics.

Most of the studies (63 articles, 72\%) draw empirical data from top management (executive board or senior managers) and neglect other members of the procurement team.
However, organizational decision making involves multiple stakeholders from inside and outside the organization (Heckman, 2003; Verville and Halingten, 2003). Each stakeholder group shapes the decision process and outcome; engages in different activities, possesses specific decision rights, responsibilities, and information needs; and pursues a unique set of goals (Webster and Wind, 1972; Howcroft and Light, 2010; Bidwell, 2012; Harnisch et al., 2013; Winkler and Brown, 2013). For instance, a legal department may require different information and may have different requirements for cloud services than an IT department or the business unit (Schneider et al., 2014). In particular, because of the peculiarities of CC, such as the changed role of the IT department and the adapted decision processes, research adopting the perspectives of multiple stakeholders regarding cloud-sourcing decisions might yield fruitful results. None of the articles investigated in this study adopts a multi-level perspective and evaluates differences in determinant factors between stakeholder groups or between hierarchical levels in a company. We therefore propose that future research adopt a multistakeholder perspective and evaluate differences in stakeholder perceptions. This suggestion is consistent with recent calls for research on CC, ITO, and packaged software acquisition (Benlian et al., 2009; Howcroft and Light, 2010; Bidwell, 2012).

Table 5 summarizes our discussion and proposes future research directions.

\section{Limitations}

This research has certain limitations. First, we conducted a systematic literature review to derive the determinant factors of cloud-sourcing decisions. Our results inform a set of determinant factors to provide a basis for further research on cloud-sourcing decisions. Although our derived set of determinant factors does not depict the interdependencies, mediation, or moderation effects of factors, we provide suggestions regarding the moderating or interaction effects among the factors in our discussion (see Table 4 for a summary). Second, the process of selecting studies may also generate discussion. For articles focusing on ITO, authors do not always specify the type of ITO decision on which the article focuses. Some studies examine mixed types of outsourcing activities, for instance, by combining software development outsourcing and datacenter operations in a single sample, or do not clearly define the type of outsourcing that they investigate. However, by having two researchers review each article, we aimed to reduce the subjectivity of the article selection. Third, the body of knowledge considered for this research is limited to the keyword search within the top 50 publications of the AIS journal ranking and selected conferences. By applying forward and backward search processes, we aimed to mitigate this limitation. Although we cannot guarantee that we identified every CC and ITO article that investigates sourcing decisions, we are confident that we achieved good and reasonable coverage, which is preferred to 'a comprehensive one that would make a review process at best ephemeral if not unachievable' (Rowe, 2014: 246). Finally, we acknowledge that our coding may be subjective to a certain extent. In particular, this subjectivity may arise if researchers do not clearly define the variables that are used or if the definitions of the author variables to map on a master variable are ambiguous. 
- Incorporate determinant factors from Figure 1 in future research

- Consider factors from the non-technology context for cloud-sourcing decisions

- Consider 'good' predictors of cloud-sourcing decisions in the ITO context

- Consider 'good' predictors of ITO decisions in the CC context

- Empirically clarify the reasons for the inconclusive findings between the determinant factors of cloud-sourcing decisions and the determinant factors of ITO decisions and incorporate the suggested factors into context-specific future research (see Table 4)

- Conduct in-depth research (e.g., field or case studies) to identify how and why differences manifest between CC and ITO (e.g., decision processes)

- Conduct inter-group comparative research to clarify context-specific deviations

- Conduct service-model specific research to identify differences in the determinant factors between service models (particularly IaaS and PaaS)

- Address gaps identified in research on CC and ITO decision making

- Apply micro-level theories and focus on individual-level sourcing decisions

- Apply multi-stakeholder perspectives to evaluate differences in stakeholder perceptions regarding determinant factors

However, we are confident about the reliability and validity of our findings because of the rigorous coding approach based on independent coding by two researchers and discussion of diverging variable coding.

\section{Conclusion}

In this work, we conducted a systematic literature review, surveyed and synthesized prior empirical research concerning decision making in the CC and ITO contexts, and examined the rich body of research on ITO to identify determinant factors of sourcing decisions in the CC context. We linked the ITO literature with the CC literature and discussed what the CC literature can learn from the ITO literature (i.e., which findings are transferable and which findings might need reconsideration). We then discussed whether the peculiarities of CC can explain differences between the determinant factors of ITO decisions and the determinant factors of cloudsourcing decisions. We extracted the most frequently studied determinant factors with robust results, discussed the inconclusive findings, identified gaps in the literature, and suggested paths for future research. Furthermore, we discussed interdependencies between the variables and peculiarities of CC that may elucidate the inconsistent findings in prior research. Therefore, the article serves as both a repository of past research and a guide for future research.

The contribution of this review is threefold. First, we derived a set of determinant factors of cloud-sourcing decisions from research within the IS community. Our results provide a basis for future research in the CC context and contribute to the development of theory in the IS domain. We thereby answer the call of Lacity et al. (2011) for the development of an 'endogenous ITO theory rather than continuing to rely heavily on reference discipline theories' (p. 147). IS researchers can draw from our derived set of determinant factors of cloud-sourcing decisions to advance research on decision making or acquisition in the field of CC. By discussing inconclusive findings regarding the determinant factors of cloud-sourcing decisions, we identified contextual factors that are specific to the CC sourcing model and that may alter the influence of specific determinant factors of sourcing decisions. Based on these discussions, we provided concrete paths for future research endeavors. Second, we applied a method developed in IS research (Jeyaraj et al., 2006) and demonstrated its applicability to a different research setting. Third, our work contributes to practice, as the determinant factors of cloud-sourcing decisions serve as a basis for practitioner-oriented guidelines and best practices regarding how to select and offer cloud services. Furthermore, practitioners may use the set of determinant factors to guide their procurement processes and to identify challenges that may arise during the adoption, acquisition, or integration of cloud services.

\section{Acknowledgements}

The research was conducted in context of the Value4Cloud research project, funded by the German Federal Ministry for Economics and Technology (grant no. 01MD11043A). The authors would like to thank Jens Lansing and Sebastian Lins for their assistance with this research and their constructive feedback on previous drafts of this paper. We also would like to thank the Senior Editor and anonymous reviewers for their valuable comments and suggestions to improve the quality of this paper.

\section{References}

Aggarwal, R. and Singh, H. (2013). Differential Influence of Blogs across Different Stages of Decision Making: The case of venture capitalists, MIS Quarterly 37(4): 1093-1112.

Akhilesh, B. (2000). A Study of Senior Information Systems Managers' Decision Models in Adopting New Computing Architectures, Journal of the AIS 1(1): 1-56.

Al-Qirim, N.A. (2003). The Strategic Outsourcing Decision of IT and Ecommerce: The case of small businesses in New Zealand, Journal of Information Technology Cases And Applications 5(3): 32-56.

Alaghehband, F.K., Rivard, S., Wu, S. and Goyette, S. (2011). An Assessment of the Use of Transaction Cost Theory in Information Technology Outsourcing, The Journal of Strategic Information Systems 20(2): 125-138.

Ang, S. and Cummings, L.L. (1997). Strategic Response to Institutional Influences on Information Systems Outsourcing, Organization Science 8(3): 235-256.

Ang, S. and Straub, D.W. (1998). Production and Transaction Economies and IS Outsourcing: A study of the U.S. banking industry, MIS Quarterly 22(4): 535-552.

Apte, U.M., Sobol, M.G., Hanaoka, S., Shimada, T., Saarinen, T., Salmela, T. and Vepsalainen, A.P.J. (1997). IS Outsourcing Practices in the USA, Japan and Finland: A comparative study, Journal of Information Technology 12(4): 289-304.

Arlbjørn, J.S. and Freytag, P.V. (2012). Public Procurement vs Private Purchasing: Is there any foundation for comparing and learning across the sectors? International Journal of Public Sector Management 25(3): 203-220. 
com/doc/1542615/survey-analysis-north-american-midsize (accessed 6 November 2012).

Lee, G., Patterson, D., Rabkin, A., Stoica, I. and Zaharia, M. (2010). A View of Cloud Computing, Communications of the ACM 53(4): 50-58.

Asatiani, A., Apte, U.M., Penttinen, E., Ronkko, M. and Saarinen, T. (2014) Outsourcing of Disaggregated Services in Cloud-Based Enterprise Information Systems, in Proceedings of the 47th Hawaii International Conference on System Sciences (Big Island, Hawaii, USA).

Association for Information Systems. (2005). MIS journal rankings [www document] http://www.aisnet.org/?JournalRankings (accessed 8 August 2014).

Association for Information Systems. (2011). Senior scholars' basket of journals [www document] http://www.aisnet.org/?SeniorScholarBasket (accessed 8 August 2014)

Aubert, B.A., Beaurivage, G., Croteau, A.-M. and Rivard, S. (2008). Firm Strategic Profile and IT Outsourcing, Information Systems Frontiers 10(2): 129-143.

Aubert, B.A., Houde, J.-F., Patry, M. and Rivard, S. (2012). A Multi-Level Investigation of Information Technology Outsourcing, The Journal of Strategic Information Systems 21(3): 233-244.

Aubert, B.A., Rivard, S. and Patry, M. (1996). A Transaction Cost Approach to Outsourcing Behavior: Some empirical evidence, Information \& Management 30 (2): 51-64.

Aubert, B.A., Rivard, S. and Patry, M. (2004). A Transaction Cost Model of IT Outsourcing, Information \& Management 41(7): 921-932.

Badger, L., Grance, T., Patt-Corner, R. and Voas, J. (2012). Cloud computing synopsis and recommendations [www document] http://csrc.nist.gov/ publications/nistpubs/800-146/sp800-146.pdf (accessed 6 November 2012).

Baldwin, L.P., Irani, Z. and Love, P.E.D. (2001). Outsourcing Information Systems: Drawing lessons from a banking case study, European Journal of Information Systems 10(1): 15-24.

Benlian, A. (2009). A Transaction Cost Theoretical Analysis of Software-as-aService (SaaS)-Based Sourcing in SMBs and Enterprises, in Proceedings of the 17th European Conference on Information Systems (Verona, Italy).

Benlian, A. and Hess, T. (2011). Opportunities and Risks of Software-as-a-Service: Findings from a survey of IT executives, Decision Support Systems 52(1): 232-246.

Benlian, A., Hess, T. and Buxmann, P. (2009). Drivers of SaaS-Adoption - An empirical study of different application types, Business \& Information Systems Engineering 1(5): 357-369.

Bennett, C. and Timbrell, G.T. (2000). Application Service Providers: Will they succeed? Information Systems Frontiers 2(2): 195-211.

Berg, B. and Stylianou, A.C. (2009). Factors Considered when Outsourcing an IS System: An empirical examination of the impacts of organizational size, strategy and the object of a decision, European Journal of Information Systems 18(3): 235-248.

Bernnat, R., Zink, W., Bieber, N., Strach, J. and Tsai, S. (2012). The standardisation environment for cloud computing [www document] http:// www.bmwi.de/English/Redaktion/Pdf/normungs-undstandardisierungsumfeld-von-cloud-computing (accessed 14 April 2012).

Bharadwaj, A.S. (2000). A Resource-Based Perspective on Information Technology Capability and Firm Performance: An empirical investigation, MIS Quarterly 24(1): 169-196.

Bidwell, M.J. (2012). Politics and Firm Boundaries: How organizational structure, group interests, and resources affect outsourcing, Organization Science 23(6): 1622-1642.

Blaskovich, J. and Mintchik, N. (2010). Accounting Executives and IT Outsourcing Recommendations: An experimental study of the effect of CIO skills and institutional isomorphism, Journal of Information Technology 26(2): 139-152.

Boehler, N.B. and Ramos, G.A. (2014). US/EU Data Protection Conflicts: Whither safe harbor? For The Defense 56(4): 62-67.

Borgman, H.P., Bahli, B., Heier, H. and Schewski, F. (2013). Cloudrise: Exploring cloud computing adoption and governance with the TOE framework, in Proceedings of the 46th Hawaii International Conference on System Sciences (Maui, Hawaii, USA).

Brcar, F. and Bukovec, B. (2013). Analysis of Increased Information Technology Outsourcing Factors, Organizacija 46(1): 13-19.

Brender, N. and Markov, I. (2013). Risk Perception and Risk Management in Cloud Computing: Results from a case study of Swiss companies, International Journal of Information Management 33(5): 726-733.

Browning, J.A. and MacDonald, N. (2011). Survey analysis: North American midsize businesses cite cloud intentions [www document] http://www.gartner.
Chen, P.-y. and Wu, S.-y. (2013). The Impact and Implications of On-Demand Services on Market Structure, Information Systems Research 24(3): 750-767.

Clark, T.D., Zmud, R.W. and McCray, G.E. (1995). The Outsourcing of Information Services: Transforming the nature of business in the information industry, Journal of Information Technology 10(4): 221-237.

Cloud Security Alliance. (2013). NSA/PRISM Survey [www document] http:// www.cloudsecurityalliance.org/research/surveys/\#_nsa_prism (accessed 28 June 2013).

Collins, J.S. and Millen, R.A. (1995). Information Systems Outsourcing by Large American Industrial Firms: Choices and impacts, Information Resources Management Journal 8(1): 5-13.

Cullen, S., Seddon, P.B. and Willcocks, L.P. (2005). IT Outsourcing Configuration: Research into defining and designing outsourcing arrangements, The Journal of Strategic Information Systems 14(4): 357-387.

Currie, W.L., Desai, B. and Khan, N. (2004). Customer Evaluation of Application Services Provisioning in Five Vertical Sectors, Journal of Information Technology 19(1): 39-58.

Daylami, N., Ryan, T., Olfman, L. and Shayo, C. (2005). Determinants of Application Service Provider (ASP) Adoption As an Innovation, in Proceedings of the 38th Hawaii International Conference on System Sciences (Big Island, Hawaii, USA).

de Looff, L.A. (1995). Information Systems Outsourcing Decision Making: A framework, organizational theories and case studies, Journal of Information Technology 10(4): 281-297.

Dhar, S. and Balakrishnan, B. (2006). Risks, Benefits, and Challenges in Global IT Outsourcing: Perspectives and practices, Journal of Global Information Management 14(3): 39-69.

Diana, M.L. (2009). Exploring Information Systems Outsourcing in U.S. HospitalBased Health Care Delivery Systems, Health Care Management Science 12(4): 434-450.

Dias Ferreira, A.M. and Barbin Laurindo, F.J. (2009). Outsourcing DecisionMaking Aspects Considered by IT Departments in Brazilian Companies, International Journal of Production Economics 122(1): 305-311.

Dibbern, J., Chin, W.W. and Heinzl, A. (2012). Systemic Determinants of the Information Systems Outsourcing Decision: A comparative study of German and United States firms, Journal of the AIS 13(6): 466-497.

Dibbern, J., Goles, T., Hirschheim, R.A. and Jayatilaka, B. (2004). Information Systems Outsourcing: A survey and analysis of the literature, The DATA BASE for Advances in Information Systems 35(4): 6-102.

Dibbern, J. and Heinzl, A. (2009). Outsourcing of Information Systems Functions in Small and Medium Sized Enterprises: A test of a multi-theoretical model, Business \& Information Systems Engineering 1(1): 101-110.

Dibbern, J., Heinzl, A. and Leibbrandt, S. (2003). Interpreting the IS Sourcing Decision: The hidden impetus and limitation of economic forces, Wirtschaftsinformatik 45(5): 533-540.

DiMaggio, P.J. and Powell, W.W. (1983). The Iron Cage Revisited: Institutional isomorphism and collective rationality in organizational fields, American Sociological Review 48(2): 147-160.

Dimoka, A., Hong, Y. and Pavlou, P. (2012). On Product Uncertainty in Online Markets: Theory and evidence, MIS Quarterly 36(2): 395-426.

Ekanayaka, Y., Currie, W.L. and Seltsikas, P. (2003). Evaluating Application Service Providers, Benchmarking: An International Journal 10(4): 343-354.

Ermakova, T., Huenges, J., Erek, K. and Zarnekow, R. (2013). Cloud Computing in Healthcare - A literature review on current state of research, in Proceedings of the 19th Americas Conference on Information Systems (Chicago, Illinois, USA).

Espino-Rodríguez, T.F. and Gil-Padilla, A.M. (2005). Determinants of Information Systems Outsourcing in Hotels from the Resource-Based View: An empirical study, International Journal of Tourism Research 7(1): 35-47.

European Network and Information Security Agency. (2011). Security \& resilience in governmental clouds [www document] http://www.enisa.europa .eu/act/rm/emerging-and-future-risk/deliverables/security-and-resiliencein-governmental-clouds (accessed 6 November 2012).

Fiedler, M., Tuschke, A., Pfaller, R. and Picot, A. (2013). Rules of Efficiency or Legitimacy? Antecedents of IT-Outsourcing - A longitudinal approach, in Proceedings of the 21st European Conference on Information Systems (Utrecht, The Netherlands).

Fisher, J., Hirschheim, R.A. and Jacobs, R. (2008). Understanding the Outsourcing Learning Curve: A longitudinal analysis of a large Australian company, Information Systems Frontiers 10(2): 165-178. 
Foster, I., Zhao, Y., Raicu, I. and Lu, S. (2008). Cloud Computing and Grid Computing 360-Degree Compared, in Proceedings of the Grid Computing Environments Workshop (Austin, Texas, USA)

Fowler, A. and Jeffs, B. (1998). Examining Information Systems Outsourcing: A case study from the United Kingdom, Journal of Information Technology 13(2): 111-126.

Fulk, J. (1993). Social Construction of Communication Technology, Academy of Management Journal 36(5): 921-950.

Gefen, D., Pavlou, P., Benbasat, I., McKnight, H. and Stewart, K. (2006). Should Institutional Trust Matter in Information Systems Research? Communications of the AIS 17(1): 205-222.

General Services Administration. (2012). Federal risk and authorization management program [www document] http://cloud.cio.gov/fedramp (accessed 24 February 2014).

Giessmann, A. and Stanoevska, K. (2012). Platform as a Service - A conjoint study on consumers' preferences, in Proceedings of the 33rd International Conference on Information Systems (Orlando, Florida, USA).

Gonzalez, R., Gasco, J. and Llopis, J. (2005a). Information Systems Outsourcing Reasons in the Largest Spanish Firms, International Journal of Information Management 25(2): 117-136.

Gonzalez, R., Gasco, J. and Llopis, J. (2005b). Information Systems Outsourcing Risks: A study of large firms, Industrial Management \& Data Systems 105(1) $45-62$

Gorla, N. and Lau, M.B. (2010). Will Negative Experiences Impact Future IT Outsourcing? Journal of Computer Information Systems 50(3): 91-101.

Guenther, O. and Tamm, G. (2002). Web Based Services: An empirical study of their adoption and penetration, in Proceedings of the 10th European Conference on Information Systems (Gdansk, Poland).

Gupta, P., Seetharaman, A. and Raj, J.R. (2013). The Usage and Adoption of Cloud Computing by Small and Medium Businesses, International Journal of Information Management 33(5): 861-874.

Hall, J.A. and Liedtka, S.L. (2005). Financial Performance, CEO Compensation, and Large-Scale Information Technology Outsourcing Decisions, Journal of Management Information Systems 22(1): 193-221.

Hancox, M. and Hackney, R. (2000). IT Outsourcing: Frameworks for conceptualizing practice and perception, Information Systems Journal 10(3): 217-237.

Harnisch, S., Kaiser, J. and Buxmann, P. (2013). Technological Frames of Reference in Software Acquisition Decisions: Results of a multiple case study, in Proceedings of the 34th International Conference on Information Systems (Milan, Italy).

Heart, T. (2007). Empirically Testing a Model for the Intention of Firms to Use Remote Application Hosting, in Proceedings of the 15th European Conference on Information Systems (St. Gallen, Switzerland).

Heart, T. (2010). Who is Out There? Exploring the Effects of Trust and Perceived Risk on SaaS Adoption Intentions, The DATA BASE for Advances in Information Systems 41(3): 49-68.

Heckman, R.L. (2003). Managing the IT Procurement Process, in C.V. Brown and H. Topi (eds.) IS Management Handbook, Washington, DC: Auerbach Publications, pp. 73-88.

Hoberg, P., Wollersheim, J. and Krcmar, H. (2012). The Business Perspective on Cloud Computing - A literature review of research on cloud computing, in Proceedings of the 18th Americas Conference on Information Systems (Seattle, Washington, USA).

Howcroft, D. and Light, B. (2010). The Social Shaping of Packaged Software Selection, Journal of the AIS 11(3): 122-148.

Hu, Q., Saunders, C. and Gebelt, M. (1997). Research Report: Diffusion of information systems outsourcing: A reevaluation of influence sources, Information Systems Research 8(3): 288-301.

International Organization for Standardization. (2013). ISO/IEC WD 27017 [www document] http://www.iso.org/iso/home/store/catalogue_tc/ catalogue_detail.htm?csnumber=43757 (accessed 15 March 2014).

Jain, A. and Thietart, R.-A. (2013). Knowledge Based Transactions and Decision Framing in Information Technology Outsourcing, The Journal of Strategic Information Systems 22(4): 315-327.

Jansen, W. and Grance, T. (2011). Guidelines on Security and Privacy in Public Cloud Computing [www document] http://csrc.nist.gov/publications/nistpubs/ 800-144/SP800-144.pdf (accessed 20 January 2012).

Janssen, M. and Joha, A. (2011). Challenges for Adopting Cloud-Based Software as a Service (SaaS) in the Public Sector, in Proceedings of the 19th European Conference on Information Systems (Helsinki, Finland).
Jayatilaka, B., Schwarz, A. and Hirschheim, R.A. (2003). Determinants of ASP Choice: An integrated perspective, European Journal of Information Systems 12(3): 210-224.

Jeyaraj, A., Rottman, J.W. and Lacity, M.C. (2006). A Review of the Predictors, Linkages, and Biases in IT Innovation Adoption Research, Journal of Information Technology 21(1): 1-23.

Kakabadse, A. and Kakabadse, N. (2002). Application Service Providers (ASPs): New impetus for transformational change, Knowledge and Process Management 9(4): 205-218.

Kans, M. (2012). Impact of IT Procurement on the Quality of the Maintenance Process: Results from a study in Swedish industry, Journal of Quality in Maintenance Engineering 18(2): 196-215.

Kern, T., Kreijger, J. and Willcocks, L. (2002). Exploring ASP as Sourcing Strategy: Theoretical perspectives, propositions for practice, The Journal of Strategic Information Systems 11(2): 153-177.

Khorshed, M.T., Ali, A.B.M.S. and Wasimi, S.A. (2012). A Survey on Gaps, Threat Remediation Challenges and Some Thoughts for Proactive Attack Detection in Cloud Computing, Future Generation Computer Systems 28(6): 833-851.

Kishore, R., Agrawal, M. and Rao, H.R. (2005). Determinants of Sourcing during Technology Growth and Maturity: An empirical study of e-commerce sourcing, Journal of Management Information Systems 21(3): 47-82.

Koehler, P., Anandasivam, A., Dan, M.A. and Weinhardt, C. (2010). Customer Heterogeneity and Tariff Biases in Cloud Computing, in Proceedings of the 31st International Conference on Information Systems (Saint Louis, Missouri, USA).

Kung, L., Cegielski, C. and Kung, H.-J. (2013). Environmental Pressure on Software as a Service Adoption: An integrated perspective, in Proceedings of the 19th Americas Conference on Information Systems (Chicago, Illinois, USA).

Lacity, M.C. and Hirschheim, R.A. (1993a). The Information Systems Outsourcing Bandwagon, Sloan Management Review 35(1): 73-86.

Lacity, M.C. and Hirschheim, R.A. (1993b). Information Systems Outsourcing: Myths, metaphors and realities, Chichester: Wiley.

Lacity, M.C., Khan, S., Yan, A. and Willcocks, L.P. (2010). A Review of the IT Outsourcing Empirical Literature and Future Research Directions, Journal of Information Technology 25(4): 395-433.

Lacity, M.C., Khan, S.A. and Willcocks, L.P. (2009). A Review of the IT Outsourcing Literature: Insights for practice, The Journal of Strategic Information Systems 18(3): 130-146.

Lacity, M.C. and Willcocks, L.P. (1998). An Empirical Investigation of Information Technology Sourcing Practices: Lessons from experience, MIS Quarterly 22(3): 363-408.

Lacity, M.C. and Willcocks, L.P. (2013). Outsourcing Business Processes for Innovation, MIT Sloan Management Review 54(3): 62-69.

Lacity, M.C., Willcocks, L.P. and Khan, S. (2011). Beyond Transaction Cost Economics: Towards an endogenous theory of information technology outsourcing, The Journal of Strategic Information Systems 20(2): 139-157.

Lansing, J., Schneider, S. and Sunyaev, A. (2013). Cloud Service Certifications: Measuring consumers' preferences for assurances, in Proceedings of the 21st European Conference on Information Systems (Utrecht, The Netherlands).

Lechesa, M., Seymour, L. and Schuler, J. (2011). ERP Software as Service (SaaS): Factors affecting adoption in South Africa, in Proceedings of the 5th International Conference on Research and Practical Issues of Enterprise Information Systems (Aalborg, Denmark).

Lee, S.-G., Chae, S.H. and Cho, K.M. (2013). Drivers and Inhibitors of SaaS Adoption in Korea, International Journal of Information Management 33(3): 429-440.

Leimeister, S., Böhm, M., Riedl, C. and Krcmar, H. (2010). The Business Perspective of Cloud Computing: Actors, roles, and value networks, in Proceedings of the 18th European Conference on Information Systems (South Africa, Pretoria).

Lessin, J.E. (2013). Age rises for some tech-firm founders [www document] http:// online.wsj.com/article/SB10001424127887324000704578389103697378458.html (accessed 6 October 2013).

Li, Y., Tan, C.-H., Teo, H.-H. and Tan, B.C.Y. (2006). Innovative Usage of Information Technology in Singapore Organizations: Do CIO characteristics make a difference? IEEE Transactions on Engineering Management 53(2): 177-190.

Li, Z., Zhang, H., O’Brien, L., Cai, R. and Flint, S. (2013). On Evaluating Commercial Cloud Services: A systematic review, Journal of Systems and Software 86(9): 2371-2393. 
Lian, J.-W., Yen, D.C. and Wang, Y.-T. (2014). An Exploratory Study to Understand the Critical Factors Affecting the Decision to Adopt Cloud Computing in Taiwan Hospital, International Journal of Information Management 34(1): 28-36.

Lin, A. and Chen, N.-C. (2012). Cloud Computing as an Innovation: Percepetion, attitude, and adoption, International Journal of Information Management 32(6): 533-540.

Loebbecke, C. and Huyskens, C. (2006). What Drives Netsourcing Decisions? An Empirical Analysis, European Journal of Information Systems 15(4): $415-423$.

Loh, L. and Venkatraman, N. (1992a). Determinants of Information Technology Outsourcing: A cross-sectional analysis, Journal of Management Information Systems 9(1): 7-24.

Loh, L. and Venkatraman, N. (1992b). Diffusion of Information Technology Outsourcing: Influence sources and the Kodak effect, Information Systems Research 3(4): 334-358.

Loh, L. and Venkatraman, N. (1995). An Empirical Study of Information Technology Outsourcing: Benefits, risks, and performance implications, in Proceedings of the 16th International Conference on Information Systems (Amsterdam, The Netherlands).

Low, C., Chen, Y. and Wu, M. (2011). Understanding the Determinants of Cloud Adoption, Industrial Management \& Data Systems 111(7): 1006-1023.

Malladi, S. and Krishnan, M.S. (2012). Cloud Computing Adoption and its Implications for CIO Strategic Focus - An empirical analysis, in Proceedings of the 33rd International Conference on Information Systems (Orlando, Florida, USA).

Marston, S., Li, Z., Bandyopadhyay, S., Zhang, J. and Ghalsasi, A. (2011). Cloud Computing - The business perspective, Decision Support Systems 51(1): 176-189.

Martens, B., Poeppelbuss, J. and Teuteberg, F. (2011). Understanding the Cloud Computing Ecosystem: Results from a quantitative content analysis, in Proceedings of the Wirtschaftsinformatik (Zürich, Switzerland).

Martens, B. and Teuteberg, F. (2009). Why Risk Management Matters in IT Outsourcing - A systematic literature review and elements of a research agenda, in Proceedings of the 17th European Conference on Information Systems (Verona, Italy).

Martens, B. and Teuteberg, F. (2011). Decision-Making in Cloud Computing Environments: A cost and risk based approach, Information Systems Frontiers 14(4): 871-893.

McGeogh, B.T. and Donnellan, B. (2013). Factors that Affect the Adoption of Cloud Computing for an Enterprise: A case study of cloud adoption within Intel Corporation, in Proceedings of the 21st European Conference on Information Systems (Utrecht, The Netherlands).

McIvor, R.T. and Humphreys, P.K. (2000). A Case-Based Reasoning Approach to the Make or Buy Decision, Integrated Manufacturing Systems 11(5): 295-310.

McLellan, K., Marcolin, B.L. and Beamish, P.W. (1995). Financial and Strategic Motivations behind IS Outsourcing, Journal of Information Technology 10(4): 299-321.

Mell, P. and Grance, T. (2011). A NIST definition of cloud computing [www document] http://csrc.nist.gov/publications/nistpubs/800-145/SP800-145.pdf (accessed 6 November 2012).

Miles, R.E. and Snow, C.C. (1978). Organizational Strategy, Structure, and Process, New York: McGraw-Hill.

Morabito, V. (2003). An Empirical Investigation of Determinants to Buy Application Services from ASPs, in Proceedings of the 11th European Conference on Information Systems (Naples, Italy).

Morgan, L. and Conboy, K. (2013). Factors Affecting the Adoption of Cloud Computing: An exploratory study, in Proceedings of the 21st European Conference on Information Systems (Utrecht, The Netherlands).

Moses, A. and Åhlström, P. (2008). Problems in Cross-Functional Sourcing Decision Processes, Journal of Purchasing and Supply Management 14(2): 87-99.

Nam, K., Rajagopalan, S., Rao, H.R. and Chaudhury, A. (1996). A Two-Level Investigation of Information Systems Outsourcing, Communications of the ACM 39(7): $36-44$.

Narasimhan, B. and Nichols, R. (2011). State of Cloud Applications and Platforms: The cloud adopters' view, Computer 44(3): 24-28.

Narayandas, D. (2005). Building Loyalty in Business Markets, Harvard Business Review 83(9): 131-139.
Paraskevas, A. and Buhalis, D. (2002). Outsourcing IT for Small Hotels: The opportunities and challenges of using application service providers, Cornell Hotel And Restaurant Administration Quarterly 43(2): 27-39.

Pinnington, A. and Woolcock, P. (1995). How Far is IS/IT Outsourcing Enabling New Organizational-Structure and Competences? International Journal of Information Management 15(5): 353-365.

Pollock, N. and Williams, R. (2007). Technology Choice and its Performance: Towards a sociology of software package procurement, Information and Organization 17(3): 131-161.

Porter, M.E. (1998). Competitive strategy: Techniques for analyzing industries and competitors, New York: Free Press.

Qu, W.G. and Pinsonneauli, A. (2011). Country Environments and the Adoption of IT Outsourcing, Journal of Global Information Management 19(1): 30-50.

Qu, W.G., Pinsonneault, A. and Oh, W. (2011). Influence of Industry Characteristics on Information Technology Outsourcing, Journal of Management Information Systems 27(4): 99-128.

Ragowsky, A., Licker, P., Miller, J., Gefen, D. and Stern, M. (2014). Do Not Call Me Chief Information Officer, But Chief Integration Officer: A summary of the 2011 Detroit CIO roundtable, Communications of the AIS 34(1): 1333-1346.

Ramgovind, S., Eloff, M.M. and Smith, E. (2010). The Management of Security in Cloud Computing, in Proceedings of the Information Security for South Africa (Johannesburg, South Africa).

Randeree, E., Kishore, R. and Rao, H.R. (2005). Exploring the Moderating Effect of Trust and Privacy in the Adoption of Application Service Providers in the Healthcare Industry, in Proceedings of the 38th Hawaii International Conference on System Sciences (Big Island, Hawaii, USA).

Repschlaeger, J., Wind, S., Zarnekow, R. and Turowski, K. (2012). A Reference Guide to Cloud Computing Dimensions: Infrastructure as a service classification framework, in Proceedings of the 45th Hawaii International Conference on System Sciences (Maui, Hawaii, USA).

Rieger, P., Gewald, H. and Schumacher, B. (2013). Cloud-Computing in Banking: Influential factors, benefits and risks from a decision maker's perspective, in Proceedings of the 19th Americas Conference on Information Systems (Chicago, Illinois, USA).

Rogers, E.M. (1983). Diffusion of Innovations, 3rd edn, New York: Free Press.

Rouse, A. and Corbitt, B. (2007). Understanding Information Systems Outsourcing Success and Risks through the Lens of Cognitive Biases, in Proceedings of the 15th European Conference on Information Systems (St. Gallen, Switzerland).

Rowe, F. (2014). What Literature Review Is Not: Diversity, boundaries and recommendations, European Journal of Information Systems 23(3): 241-255.

Saya, S., Pee, L.G. and Kankanhalli, A. (2010). The Impact of Institutional Influences on Perceived Technological Characteristics and Real Options in Cloud Computing Adoption, in Proceedings of the 31st International Conference on Information Systems (Saint Louis, Missouri, USA).

Schneider, S., Lansing, J., Gao, F. and Sunyaev, A. (2014). A Taxonomic Perspective on Certification Schemes: Development of a taxonomy for cloud service certification criteria, in Proceedings of the 47th Hawaii International Conference on System Sciences (Big Island, Hawaii, USA).

Schwarz, A., Jayatilaka, B., Hirschheim, R.A. and Goles, T. (2009). A Conjoint Approach to Understanding IT Application Services Outsourcing, Journal of the AIS 10(10): 748-781.

Seddon, P., Cullen, S. and Willcocks, L. (2002). Does Dombergers Theory of the Contracting Organization Explain Satisfaction with IT Outsourcing? in Proceedings of the 23rd International Conference on Information Systems (Barcelona, Spain).

Seethamraju, R. (2013). Determinants of SaaS ERP Systems Adoption, in Proceedings of the 17th Pacific Asia Conference on Information Systems (Jeju Island, Korea).

Serva, M.A., Sherer, S.A. and Sipior, J.C. (2003). 'When Do You ASP?' The Software Life Cycle Control Model, Information Systems Frontiers 5(2): 219-232.

Spink, M. (2010). Survey analysis: Global adoption of cloud computing, a view from above [www document] http://www.gartner.com/doc/1441813/surveyanalysis-global-adoption-cloud (accessed 6 November 2012).

Subashini, S. and Kavitha, V. (2011). A Survey on Security Issues in Service Delivery Models of Cloud Computing, Journal of Network and Computer Applications 34(1): 1-11.

Sunyaev, A. and Schneider, S. (2013). Cloud Services Certification, Communications of the ACM 56(2): 33-36. 
Susarla, A., Barua, A. and Whinston, A.B. (2009). A Transaction Cost Perspective of the 'Software as a Service' Business Model, Journal of Management Information Systems 26(2): 205-240.

Susarla, A., Barua, A. and Whinston, A.B. (2010). Multitask Agency, Modular Architecture, and Task Disaggregation in SaaS, Journal of Management Information Systems 26(4): 87-118.

Tanriverdi, H., Konana, P. and Ling, G. (2007). The Choice of Sourcing Mechanisms for Business Processes, Information Systems Research 18(3): 280-299.

Teng, J.T.C., Cheon, M.J. and Grover, V. (1995). Decisions to Outsource Information Systems Functions: Testing a strategy-theoretic discrepancy model, Decision Sciences 26(1): 75-103.

Tiwana, A. and Bush, A.A. (2007). A Comparison of Transaction Cost, Agency, and Knowledge-Based Predictors of IT Outsourcing Decisions: A U.S.-Japan cross-cultural field study, Journal of Management Information Systems 24(1) 259-300.

Tversky, A. and Kahneman, D. (1981). The Framing of Decisions and the Psychology of Choice, Science 211(4481): 453-458.

Venters, W. and Whitley, E.A. (2012). A Critical Review of Cloud Computing: Researching desires and realities, Journal of Information Technology 27(3): 179-197.

Verville, J. and Halingten, A. (2003). A Six-Stage Model of the Buying Process for ERP Software, Industrial Marketing Management 32(7): 585-594.

Verwaal, E., Commandeur, H. and Verbeke, W. (2008). Value Creation and Value Claiming in Strategic Outsourcing Decisions: A resource contingency perspective, Journal of Management 35(2): 420-444.

Vetter, J., Benlian, A. and Hess, T. (2011). Setting Targets Right! How Non-Rational Biases Affect the Risk Preference of IT-Outsourcing Decision Makers - An empirical investigation, in Proceedings of the 19th European Conference on Information Systems (Helsinki, Finland).

Watjatrakul, B. (2005). Determinants of IS Sourcing Decisions: A comparative study of transaction cost theory versus the resource-based view, The Journal of Strategic Information Systems 14(4): 389-415.

Webster, Jr. F.E. and Wind, Y. (1972). A General Model for Understanding Organizational Buying Behavior, Journal of Marketing 36(2): 12-19.

Webster, J. and Watson, R.T. (2002). Analyzing the Past to Prepare for the Future: Writing a literature review, MIS Quarterly 26(2): xiii-xxiii.

Weinhardt, C., Anandasivam, A., Blau, B., Borissov, N., Meinl, T., Michalk, W. and Stößer, J. (2009). Cloud Computing - A classification, business models, and research directions, Business \& Information Systems Engineering 1(5): 391-399.

Whitten, D., Chakrabarty, S. and Wakefield, R. (2010). The Strategic Choice to Continue Outsourcing, Switch Vendors, or Backsource: Do switching costs matter? Information \& Management 47(3): 167-175.

Wholey, D.R., Padman, R., Hamer, R. and Schwartz, S. (2001). Determinants of Information Technology Outsourcing among Health Maintenance Organizations, Health Care Management Science 4(3): 229-239.

Williamson, O.E. (1975). Markets and Hierarchies: Analysis and Antitrust Implications, New York: Free Press.

Williamson, O.E. (1981). The Economics of Organization: The transaction cost approach, The American Journal of Sociology 87(3): 548-577.

Williamson, O.E. (1985). The Economic Institutions of Capitalism: Firms, Markets, Relational Contracting, New York: Free Press.
Williamson, O.E. (1991). Comparative Economic Organization: The analysis of discrete structural alternatives, Administrative Science Quarterly 36(2): 269-296.

Winkler, T.J. and Brown, C.V. (2013). Horizontal Allocation of Decision Rights for On-Premise Applications and Software-as-a-Service, Journal of Management Information Systems 30(3): 13-48.

Wollersheim, J., Hoberg, P. and Krcmar, H. (2013). Procurement of Cloud Services: Seven principles to success, in Proceedings of the 13th International Research Symposium on Service Excellence in Management (Karlstad, Sweden).

Wu, W.-W., Lan, L.W. and Lee, Y.-T. (2011). Exploring Decisive Factors Affecting an Organization's SaaS Adoption: A case study, International Journal of Information Management 31(6): 556-563.

Xin, M. and Levina, N. (2008). Software-as-a-Service Model: Elaborating clientside adoption factors, in Proceedings of the 29th International Conference on Information Systems (Paris, France).

Yang, H. and Tate, M. (2012). A Descriptive Literature Review and Classification of Cloud Computing Research, Communications of the AIS 31(1): 35-60.

Yanosky, R. (2008). From Users to Choosers: The cloud and the changing shape of enterprise authority, in R. Katz (ed.) The Tower and the Cloud, Berkeley: Educause, pp. 126-136.

Yao, Y., Lee, D.M. and Lee, Y.W. (2010). Cost and Service Capability Considerations on the Intention to Adopt Application Service Provision Services, Journal of Database Management 21(3): 90-113.

\section{About the authors}

Stephan Schneider is a research assistant at the Department of Information Systems, University of Cologne, Germany. His research focuses on cloud computing, decision making in cross-functional teams for IT service procurement, as well as on certification of cloud services and the effects on strategic IT sourcing decisions. He has (co)-authored international journal articles (e.g., Communications of the ACM) and presented his work at major IS conferences (ICIS, ECIS, HICSS).

Ali Sunyaev is an assistant professor in the Department of Information Systems at the University of Cologne, Germany. His research interests include design and management of information systems, development of innovative healthcare applications, and information systems security. His work has been published in international journals such as Communications of the ACM, ACM Journal of Data and Information Quality, IEEE Software, IEEE Computer, Electronic Markets, Journal of the American Medical Informatics Association, Business and Information Systems Engineering, and Communications of the AIS. 


\section{Appendix A}

Table A1 Overview of cloud computing literature reviews

Authors Scope

(Ermakova et al., 2013)

The authors identify and categorize the state of the art in CC research in the health care domain and determine potential areas of future research. The review does not discuss determinant factors of cloud-sourcing decisions.

(Hoberg et al., 2012) The authors synthesize existing research on CC from a business perspective and structure their results according to four dimensions: CC characteristics, adoption determinants, governance mechanisms, and business impact. In the dimension adoption determinants, the authors identify six articles on cloud-sourcing decisions and summarize 17 adoption determinants but do not discuss the determinants further.

(Khorshed et al., 2012) The authors review the CC literature with focus on gaps and security concerns. They identify the top security threats, offer solutions to mitigate these threats, investigate challenges in implementing threat remediation, and propose a proactive attack detection model for CC. The review does not discuss determinant factors of cloud-sourcing decisions.

(Li et al., 2013)

(Martens et al., 2011) The authors review and synthesize the literature on evaluation of cloud services, outline state-of-the-art practices, and identify research opportunities in the context of evaluation of cloud services. The review does not discuss determinant factors of cloud-sourcing decisions. The authors apply quantitative content analysis to provide an overview of CC research. The analyzed data comprises research and practitioner-oriented articles from magazines and websites, but the authors do not discuss determinant factors of cloud-sourcing decisions.

(Venters and Whitley, 2012) The authors propose a framework to structure existing and future research on CC, which is structured around the characteristics of CC that are important for cloud customers. The framework is derived from the literature and supplemented with empirical evidence from interviews with cloud service providers and cloud service customers. The authors review the existing literature on CC and structure the literature within the proposed framework, but they do not discuss determinant factors of cloud-sourcing decisions.

(Yang and Tate, 2012) The authors propose a classification scheme to classify existing and future research on CC. The scheme consists of four main categories: technological issues, business issues, domains and applications, and conceptualizing CC. The authors classify the articles according to their scheme. They provide a short section on CC adoption, but do not discuss determinant factors of cloud-sourcing decisions.

This review

We summarize the empirical academic literature on CC and ITO by coding determinant factors that are used to explain IT sourcing decisions, compare findings on CC and ITO, and derive a set of determinant factors of cloud-sourcing decisions for future research.

\section{Appendix B}

Table B1 Journals and conference proceedings considered in the search process of the literature review and corresponding search engines queried

\begin{tabular}{lc}
\hline Journal name & Search engine \\
\hline Academy of Management Journal & EBSCOhost \\
Academy of Management Review & EBSCOhost \\
ACM Computing Surveys & EBSCOhost \\
ACM Transactions on Computation Theory & ACM Digital Library \\
ACM Transactions on Computer Systems & ACM Digital Library \\
ACM Transactions on Database Systems & ACM Digital Library \\
ACM Transactions on Embedded Computing Systems & ACM Digital Library \\
ACM Transactions on Information and System Security & ACM Digital Library \\
ACM Transactions on Information Systems & ACM Digital Library \\
ACM Transactions on Intelligent Systems and Technology & ACM Digital Library \\
ACM Transactions on Internet Technology & ACM Digital Library \\
ACM Transactions on Management Information Systems & ACM Digital Library \\
ACM Transactions on Software Engineering and Methodology & ACM Digital Library \\
ACM Transactions on the Web & ACM Digital Library \\
Administrative Science Quarterly & EBSCOhost \\
\hline
\end{tabular}




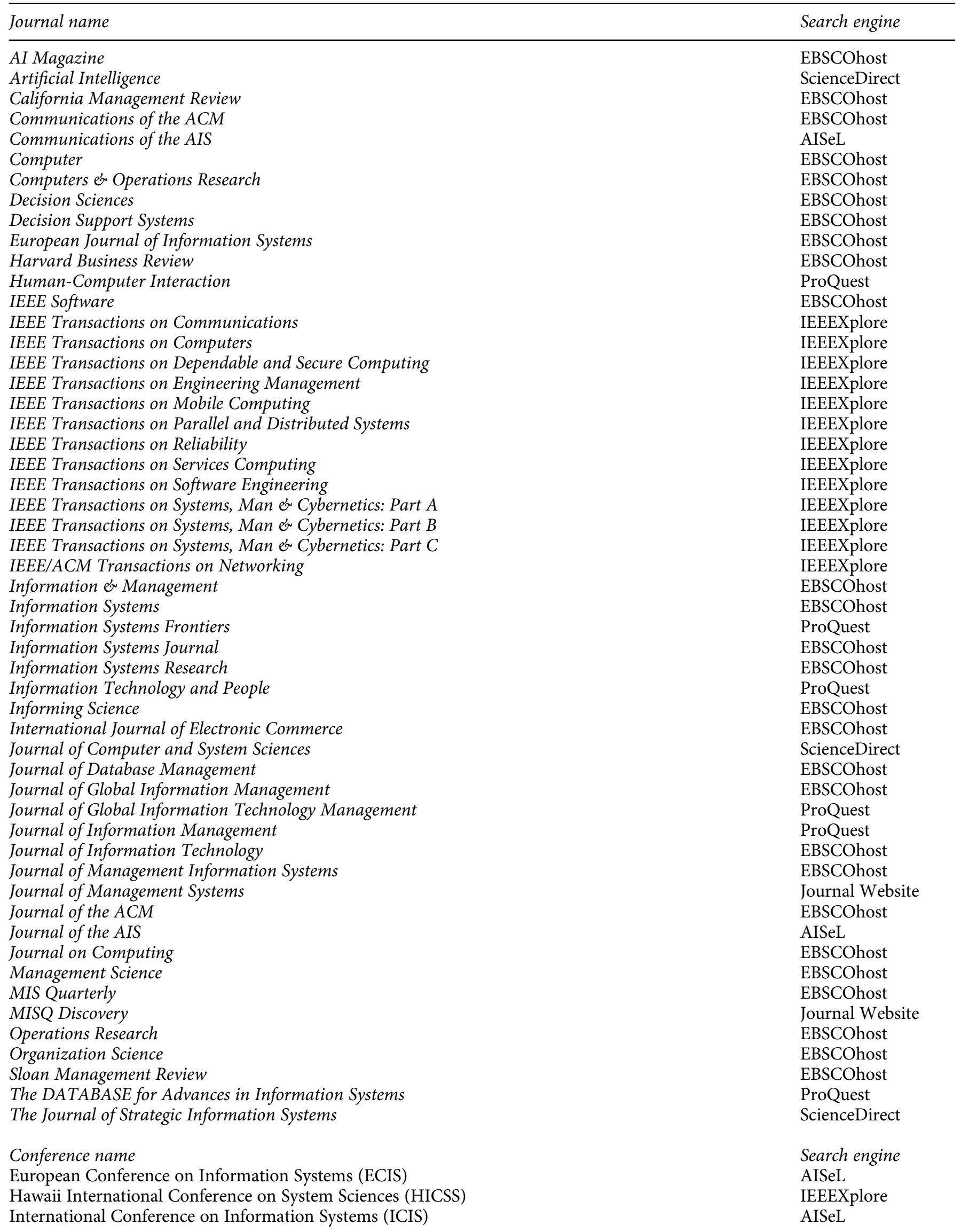




\section{Appendix C}

Table C1 Coded articles

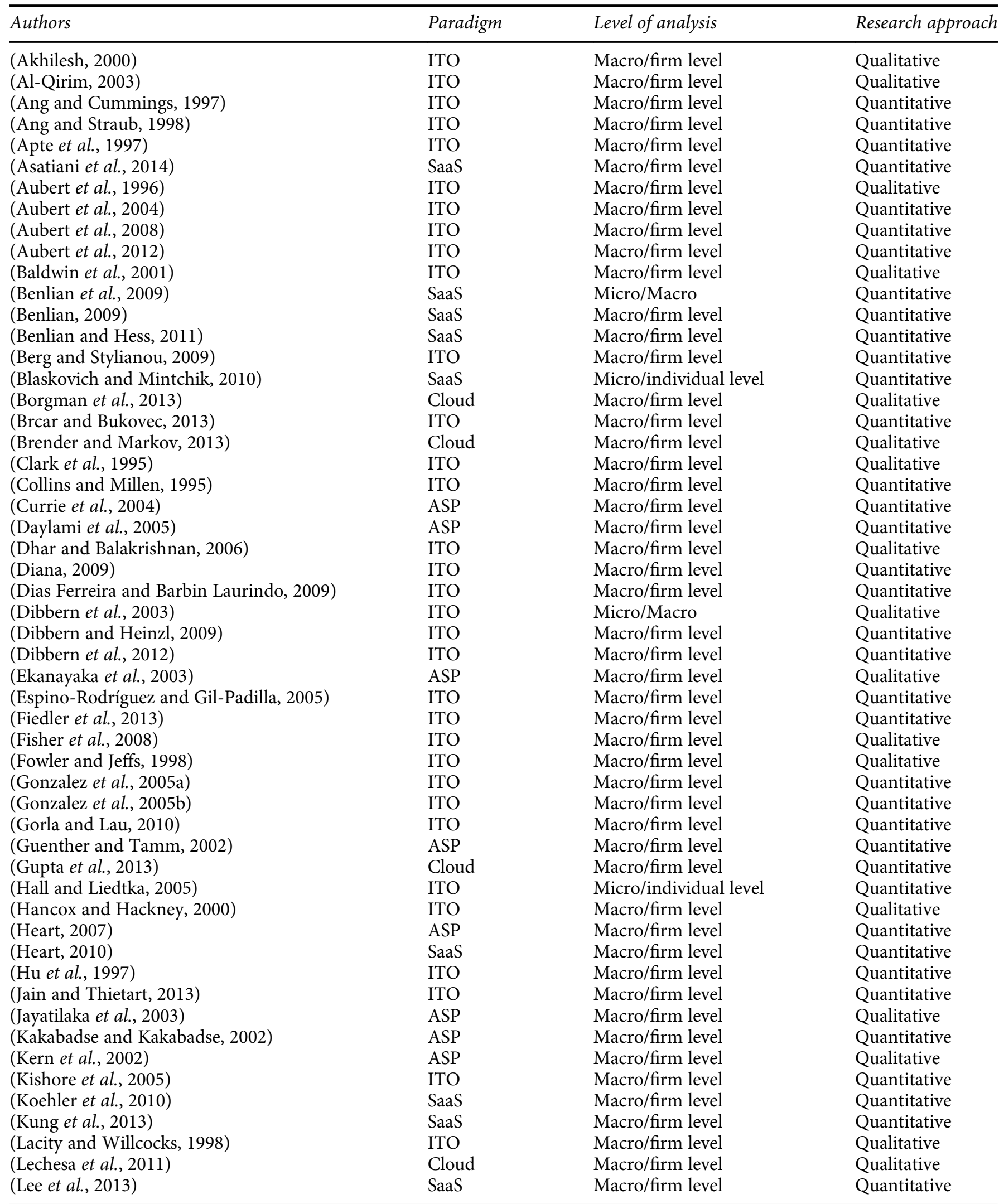


Table C1 Continued

\begin{tabular}{|c|c|c|c|}
\hline Authors & Paradigm & Level of analysis & Research approach \\
\hline (Lian et al., 2014) & Cloud & Micro/Macro & Quantitative \\
\hline (Loebbecke and Huyskens, 2006) & ASP & Macro/firm level & Quantitative \\
\hline (Loh and Venkatraman, 1992a) & ITO & Macro/firm level & Quantitative \\
\hline (Loh and Venkatraman, 1992b) & ITO & Macro/firm level & Quantitative \\
\hline (Low et al., 2011) & Cloud & Macro/firm level & Quantitative \\
\hline (McGeogh and Donnellan, 2013) & Cloud & Macro/firm level & Qualitative \\
\hline (McLellan et al., 1995) & ITO & Macro/firm level & Qualitative \\
\hline (Morabito, 2003) & ASP & Macro/firm level & Quantitative \\
\hline (Morgan and Conboy, 2013) & Cloud & Macro/firm level & Qualitative \\
\hline (Nam et al., 1996) & ITO & Macro/firm level & Quantitative \\
\hline (Qu et al., 2011) & ITO & Macro/firm level & Quantitative \\
\hline (Randeree et al., 2005) & ASP & Macro/firm level & Quantitative \\
\hline (Rieger et al., 2013) & Cloud & Macro/firm level & Qualitative \\
\hline (Rouse and Corbitt, 2007) & ITO & Micro/individual level & Qualitative \\
\hline (Saya et al., 2010) & Cloud & Macro/firm level & Quantitative \\
\hline (Schwarz et al., 2009) & ASP & Macro/firm level & Quantitative \\
\hline (Seddon et al., 2002) & ITO & Macro/firm level & Quantitative \\
\hline (Seethamraju, 2013) & SaaS & Macro/firm level & Qualitative \\
\hline (Serva et al., 2003) & ASP & Macro/firm level & Qualitative \\
\hline (Susarla et al., 2009) & ASP & Macro/firm level & Quantitative \\
\hline (Teng et al., 1995) & ITO & Macro/firm level & Quantitative \\
\hline
\end{tabular}




\section{Appendix D}

This appendix shows the coded relationships between the independent master variables and the dependent meta-variable IT sourcing decision for CC and ITO separately. For each independent master variable, the column ' + ' indicates the number of positive and significant relationships; the column '-' indicates the number of negative and significant relationships; the column ' 0 ' indicates the number of nonsignificant relationships; the column ' $M$ ' indicates the number of relationships in which the independent variable had a significant but non-directional influence on the dependent variable (e.g., when operationalized as a categorical variable). See Table 2 for detailed explanations of the coding scheme. The relationships that met the decision rule of multiple examinations (i.e., at least five times investigated) are boxed. The relationships that were examined at least five times and produced consistent results (i.e., at least $60 \%$ of the examinations produced the same results) are marked with an asterisk $\left({ }^{*}\right)$.

Table D1 Relationships between independent variables and cloud-sourcing/lTO decisions

\begin{tabular}{|c|c|c|c|c|c|c|c|c|c|c|c|}
\hline \multirow[t]{2}{*}{ Independent variable } & \multicolumn{5}{|c|}{ Cloud computing } & \multicolumn{5}{|c|}{ IT outsourcing } & \multirow[t]{2}{*}{ Total } \\
\hline & + & - & 0 & $M$ & \# & + & - & 0 & $M$ & \# & \\
\hline \multicolumn{12}{|l|}{ Asset characteristics } \\
\hline Cost savings (total) & 21 & & 5 & & $26^{x}$ & 19 & & 5 & 1 & $25^{\star}$ & 51 \\
\hline Cost savings & 10 & & 1 & & $11^{\star}$ & 9 & & 2 & & $11^{*}$ & 22 \\
\hline Production cost savings & 8 & & 3 & & $11^{\star}$ & 6 & & 2 & 1 & \begin{tabular}{|c|}
$9^{*}$ \\
\end{tabular} & 20 \\
\hline Transaction cost savings & 3 & & 1 & & 4 & 4 & & 1 & & $5^{*}$ & 9 \\
\hline Cost uncertainty & & 3 & & 1 & 4 & & 3 & 1 & & 4 & 8 \\
\hline Information intensity & 1 & & & & 1 & & & & & & 1 \\
\hline IS function & & & & & & & & & 1 & 1 & 1 \\
\hline Measurement problems & & 2 & 1 & & 3 & 1 & 8 & & & $9^{*}$ & 12 \\
\hline Need of customer contact & & 1 & & & 1 & & & & & & 1 \\
\hline Specificity (total) & 2 & 13 & 5 & & $20^{*}$ & 1 & 10 & 6 & & 17 & 37 \\
\hline Human & & & 2 & & 2 & & 5 & 4 & & 9 & 11 \\
\hline Site & & 7 & 1 & & $8^{\star}$ & & 3 & & & 3 & 11 \\
\hline Technical & 2 & 6 & 2 & & $10^{\star}$ & 1 & 2 & 2 & & 5 & 15 \\
\hline Standardization & & & & & & & & 1 & & 1 & 1 \\
\hline Strategic importance & & 6 & 2 & & $8^{*}$ & & 3 & 2 & & $5^{\star}$ & 13 \\
\hline Switching costs & & 1 & 1 & & 2 & & & & & & 2 \\
\hline Technical complexity & 1 & & & & 1 & 8 & & & & $8^{*}$ & 9 \\
\hline Transaction frequency & & & 1 & & 1 & & & & & & 1 \\
\hline Usage frequency & & 1 & 2 & & 3 & & & & & & 3 \\
\hline Asset characteristics total & 25 & 27 & 17 & 1 & 70 & 29 & 24 & 15 & 2 & 70 & 140 \\
\hline \multicolumn{12}{|l|}{ Solution characteristics } \\
\hline Abandonment options & 1 & & & & 1 & & & & & & 1 \\
\hline Contract duration & & & & & & 1 & & & & 1 & 1 \\
\hline Deferral options & & & 1 & & 1 & & & & & & 1 \\
\hline Framing & & & & & & 1 & & & & 1 & 1 \\
\hline Growth options & 1 & & & & 1 & & & & & & 1 \\
\hline Perceived contract clarity & 1 & & & & 1 & 1 & & & & 1 & 2 \\
\hline Perceived cost effectiveness & & & 1 & & 1 & & & & & & 1 \\
\hline Solution characteristics total & 3 & 0 & 2 & 0 & 5 & 3 & 0 & 0 & 0 & 3 & 8 \\
\hline \multicolumn{12}{|l|}{ Technology characteristics } \\
\hline Benefits (total) & 31 & & 6 & & $37^{*}$ & 44 & & 5 & & $49^{*}$ & 86 \\
\hline Access to specialized resources & 6 & & & & $6^{*}$ & 13 & & 1 & & $14^{*}$ & 20 \\
\hline Availability & 1 & & 2 & & 3 & & & & & & 3 \\
\hline Business performance improvement & & & & & & 2 & & & & 2 & 2 \\
\hline Flexibility & 8 & & 1 & & $9^{*}$ & 7 & & & & $7^{\star}$ & 16 \\
\hline Focus on core competencies & 4 & & & & 4 & 10 & & 3 & & $13^{*}$ & 17 \\
\hline Perceived benefits & 4 & & 2 & & $6^{*}$ & & & & & & 6 \\
\hline Quality improvements & & & & & & 10 & & & & $10^{*}$ & 10 \\
\hline Reduced time to market & 5 & & & & $5^{\star}$ & 1 & & 1 & & 2 & 7 \\
\hline Security & 1 & & 1 & & 2 & & & & & & 2 \\
\hline Transferring CAPEX to OPEX & 2 & & & & 2 & 1 & & & & 1 & 3 \\
\hline
\end{tabular}




\begin{tabular}{|c|c|c|c|c|c|c|c|c|c|c|c|}
\hline \multirow[t]{2}{*}{ Independent variable } & \multicolumn{5}{|c|}{ Cloud computing } & \multicolumn{5}{|c|}{ IT outsourcing } & \multirow[t]{2}{*}{ Total } \\
\hline & + & - & 0 & $M$ & \# & + & - & 0 & $M$ & \# & \\
\hline Data destruction & & 1 & & & 1 & & & & & & 1 \\
\hline Observability & 1 & & & & 1 & & & & & & 1 \\
\hline Perceived complexity & & 4 & 2 & & $6^{*}$ & & & & & & 6 \\
\hline Risks (total) & & 21 & 6 & & $27^{*}$ & & 5 & 1 & & $6^{*}$ & 33 \\
\hline Availability & & 3 & 2 & & $5^{\star}$ & & & & & & 5 \\
\hline Business continuity & & 1 & & & 1 & & & & & & 1 \\
\hline Loss of control & & 4 & & & 4 & & 4 & & & 4 & 8 \\
\hline Perceived risks & & 2 & 1 & & 3 & & 1 & & & 1 & 4 \\
\hline Security & & 11 & 3 & & $14^{*}$ & & & 1 & & 1 & 15 \\
\hline Traceability and auditability & 1 & & & & 1 & & & & & & 1 \\
\hline Technology characteristics total & 33 & 26 & 14 & 0 & 73 & 44 & 5 & 6 & 0 & 55 & 128 \\
\hline \multicolumn{12}{|l|}{ Client firm characteristics } \\
\hline Age & & & & & & & & & 1 & 1 & 1 \\
\hline Compatibility & 1 & & 3 & & 4 & & & & & & 4 \\
\hline Desire to restructure the organization & & & & & & 1 & & & & 1 & 1 \\
\hline Financial leverage & & & & & & & & 2 & & 2 & 2 \\
\hline Financial performance & & & & & & 3 & 2 & 3 & 1 & 9 & 9 \\
\hline Financial performance of IT function & & & & & & 1 & 2 & 2 & & 5 & 5 \\
\hline Freeze of headcount & & & & & & 1 & & & & 1 & 1 \\
\hline Industry & & & 2 & 3 & $5^{*}$ & & & 2 & 3 & $5^{*}$ & 10 \\
\hline Internal IT capabilities & 6 & 4 & 4 & & 14 & & 7 & 1 & & $8^{*}$ & 22 \\
\hline IT budget & 1 & & 1 & & 2 & & 1 & 2 & & 3 & 5 \\
\hline IT department age & & & & & & & & 1 & & 1 & 1 \\
\hline IT Department size & 1 & & 1 & & 2 & & & & 1 & 1 & 3 \\
\hline Knowledge intensity & & & & & & & 1 & & & 1 & 1 \\
\hline National characteristics & & & & 1 & 1 & & & 1 & & 1 & 2 \\
\hline New management forms & & & & & & & & & 1 & 1 & 1 \\
\hline Outsourcing expertise & & & 2 & & 2 & 1 & & 2 & & 3 & 5 \\
\hline Power of IT department & & & & & & 1 & & 1 & & 2 & 2 \\
\hline Short-term cash needs & & & & & & 1 & & 1 & & 2 & 2 \\
\hline Size & 2 & 3 & 6 & 3 & 14 & 5 & & 6 & 1 & 12 & 26 \\
\hline Strategic importance of IT & & & 1 & & 1 & & & 2 & 1 & 3 & 4 \\
\hline Strategic vulnerability & & 1 & & & 1 & & 3 & 1 & & 4 & 5 \\
\hline Strategy & 1 & & & 1 & 2 & & & 2 & 1 & 3 & 5 \\
\hline Supporting mobile workers & 1 & & & & 1 & & & & & & 1 \\
\hline Top management support & 4 & & & & 4 & 4 & 1 & & & $5^{*}$ & 9 \\
\hline Client firm characteristics total & 17 & 8 & 20 & 8 & 53 & 18 & 17 & 29 & 10 & 74 & 127 \\
\hline \multicolumn{12}{|l|}{ Individual characteristics } \\
\hline Attitude toward outsourcing & 4 & & & & 4 & 2 & & & & 2 & 6 \\
\hline CIO skills & 1 & & & & 1 & & & & & & 1 \\
\hline Cognitive dissonance & & & & & & 1 & & & & 1 & 1 \\
\hline Congruence of personal goals & & & & & & 2 & & & & 2 & 2 \\
\hline Demographics - Age & & & & & & & & 1 & & 1 & 1 \\
\hline Demographics - Educational level & & & & & & 1 & & & & 1 & 1 \\
\hline Demographics - Tenure & & & & & & & & 1 & & 1 & 1 \\
\hline Internal communication & & & & & & 2 & & & & 2 & 2 \\
\hline Personal risk preference & & & & & & 1 & & & & 1 & 1 \\
\hline Personality traits - Conscientiousness & & & & & & & & 1 & & 1 & 1 \\
\hline Personality traits - Extraversion & & & & & & 1 & & & & 1 & 1 \\
\hline Personality traits - Openness & & & 1 & & 1 & 1 & & & & 1 & 2 \\
\hline Prior outsourcing experience & & & & & & 1 & 1 & & & 2 & 2 \\
\hline Individual characteristics total & 5 & 0 & 1 & 0 & 6 & 12 & 1 & 3 & 0 & 16 & 22 \\
\hline
\end{tabular}


Table D1 Continued

\begin{tabular}{|c|c|c|c|c|c|c|c|c|c|c|c|}
\hline \multirow[t]{2}{*}{ Independent variable } & \multicolumn{5}{|c|}{ Cloud computing } & \multicolumn{5}{|c|}{ IT outsourcing } & \multirow[t]{2}{*}{ Total } \\
\hline & + & - & 0 & $M$ & \# & + & - & 0 & $M$ & \# & \\
\hline \multicolumn{12}{|l|}{ Environment characteristics } \\
\hline Availability of skilled IT personal & 1 & & 1 & & 2 & & & & & & 2 \\
\hline Capital intensity & & & & & & & 1 & & & 1 & 1 \\
\hline Competitive pressure & 2 & & 3 & & 5 & 1 & & 1 & & 2 & 7 \\
\hline Uncertainty (total) & 3 & 5 & 3 & & 11 & 3 & 7 & 3 & & 13 & 24 \\
\hline Environmental uncertainty (general) & & 3 & 1 & & 4 & 1 & 2 & & & 3 & 7 \\
\hline Environmental uncertainty (demand) & 1 & 1 & & & 2 & 1 & & & & 1 & 3 \\
\hline Environmental uncertainty (product) & 1 & 1 & & & 2 & & 2 & & & 2 & 4 \\
\hline Environmental uncertainty (technology) & 1 & & & & 1 & 1 & & 1 & & 2 & 3 \\
\hline Behavioral uncertainty & & & 2 & & 2 & & 3 & 2 & & $5^{\star}$ & 7 \\
\hline Gross domestic product (GDP) per capita & & & & & & & 1 & & & 1 & 1 \\
\hline Industry munificence & & & & & & 1 & & & & 1 & 1 \\
\hline Institution-based trust & 2 & & & & 2 & & & & & & 2 \\
\hline Institutional influences (total) & 2 & 1 & 8 & & 11 & 9 & 2 & 2 & & $13^{*}$ & 24 \\
\hline Institutional influences & & & 1 & & 1 & & & & & & 1 \\
\hline Coercive & & 1 & 3 & & 4 & & 2 & & & 2 & 6 \\
\hline Mimetic & 1 & & 3 & & 4 & 8 & & 2 & & $10^{*}$ & 14 \\
\hline Normative & 1 & & 1 & & 2 & 1 & & & & 1 & 3 \\
\hline Internet penetration & & & & & & & & 1 & & 1 & 1 \\
\hline IT intensity & & & & & & & & 1 & & 1 & 1 \\
\hline Market Maturity & 7 & & 2 & & $9^{*}$ & 5 & & 2 & & $7^{\star}$ & 16 \\
\hline Shareholder expectations & & & & & & & 1 & & & 1 & 1 \\
\hline Sharing and collaboration & 1 & & 1 & & 2 & & & & & & 2 \\
\hline Social trust & & & & & & 1 & & & & 1 & 1 \\
\hline Trading partner requirements & & & 1 & & 1 & & & & & & 1 \\
\hline Uncertainty avoidance orientation & & & & & & 1 & & & & 1 & 1 \\
\hline Environment characteristics total & 18 & 6 & 19 & 0 & 43 & 21 & 12 & 10 & 0 & 43 & 86 \\
\hline \multicolumn{12}{|l|}{ Vendor firm characteristics } \\
\hline Current investment in IT & 2 & & & & 2 & & & & & & 2 \\
\hline Financial stability & 2 & & & & 2 & & & & & & 2 \\
\hline Service capability & 8 & & 2 & & $10^{*}$ & 4 & & & & 4 & 14 \\
\hline Support & 3 & & & & 3 & 1 & & & & 1 & 4 \\
\hline Transferring risks to vendor & & & & & & 2 & & & & 2 & 2 \\
\hline Trustworthiness & 1 & & 1 & & 2 & 1 & & & & 1 & 3 \\
\hline Understanding company needs & 1 & & & & 1 & & & 1 & & 1 & 2 \\
\hline Willingness for value co-creation & 1 & 1 & & & 2 & & & & & & 2 \\
\hline Vendor firm characteristics total & 18 & 1 & 3 & 0 & 22 & 8 & 0 & 1 & 0 & 9 & 31 \\
\hline
\end{tabular}

\section{Appendix E}

\section{Master variable definitions}

\section{Asset characteristics}

Cost - Cost savings: Total cost advantage of sourcing IT resources from an external vendor compared with the costs for alternative provisioning (e.g., in-house). Total costs comprise transaction costs and production costs.

Cost - Cost savings - Production: Hardware costs, software costs, and costs related to human resources (Morabito, 2003; Serva et al., 2003; Schwarz et al., 2009).

Cost - Cost savings - Transaction: Costs of searching, creating, negotiating, maintaining, monitoring, modifying, and enforcing a service contract between clients and vendors
(Randeree et al., 2005; Schwarz et al., 2009; Dibbern et al., 2012).

Cost - Cost uncertainty: The risks associated with unpredictable costs due to the pay-per-use pricing model and limited customization possibilities of services that are not owned by the client (Benlian and Hess, 2011).

Cost - Switching costs: The costs associated with switching providers (e.g., Verwaal et al., 2008).

Information intensity: Amount of information required to successfully perform the outsourced activity (Asatiani et al., 2014).

IS function: The type of IS function to be outsourced (e.g., Wholey et al., 2001).

Measurement problems: The difficulties encountered in the evaluation of the element of exchange (Alaghehband et al., 
2011) in terms of performance measurement complexity (e.g., Loebbecke and Huyskens, 2006) or measurement difficulties (e.g., Apte et al., 1997).

Need for customer contact: Need for contact between a customer and a third party for the successful accomplishment of a task (Asatiani et al., 2014).

Specificity - Human: The business-specific knowledge required to provide the asset that arises from learning by doing (Williamson, 1981).

Specificity - Site: The degree of location dependence of an asset, for instance, when technical infrastructure requirements (e.g., specific servers) are only available within an organization's boundaries (Loebbecke and Huyskens, 2006); when data storage and processing within the asset is sensitive to potential threats such as loss of access, indiscretion, or disclosure (e.g., Loebbecke and Huyskens, 2006; Schwarz et al., 2009; Badger et al., 2012); or when legal restrictions on the data center location apply (Marston et al., 2011).

Specificity - Technical: The 'degree to which an asset can be redeployed to alternative uses and by alternative users without sacrifice of productive value' (Williamson, 1991: 281). Technical specificity also refers to the uniqueness of assets that clients require (Yao et al., 2010) or the degree of customization or individualization of assets depending on the individual requirements of an industry or a single customer (Loebbecke and Huyskens, 2006; Benlian, 2009). The range of asset specificity ranges from zero (purely generic) to complete (purely organization specific) (Williamson, 1991).

Standardization: The 'extent to which rules, procedures, and standards exist to guide the conduct of an activity and to evaluate performance' (Aubert et al., 2012: 243).

Strategic importance: The degree of strategic value that companies attach to an asset (Benlian et al., 2009). Assets of high strategic importance create and exploit unique sources of value (Loebbecke and Huyskens, 2006) and enable organizations to sustain a competitive advantage (Watjatrakul, 2005).

Technical complexity: The extent of complexity and interdependence within the hardware and software technology that is required to provide the asset (Nam et al., 1996; Kishore et al., 2005).

Transaction frequency: The frequency of how often a transaction occurs, either occasionally or recurrently (Williamson, 1975), that is, the number of recurring acquisitions of the same asset. Each acquisition involves vendor search, screening, and negotiating activities. Even one-time acquisitions of software packages may require recurring activities, such as upgrades and maintenance (Loebbecke and Huyskens, 2006).

Usage frequency: The extent of how often an asset is utilized (e.g., Benlian, 2009; Schwarz et al., 2009).

\section{Solution characteristics}

Abandonment options: The opportunity of discontinuing an investment and redeploying remaining resources effectively (e.g., Saya et al., 2010).

Contract duration: The duration of the outsourcing contract (Fiedler et al., 2013).

Deferral options: The opportunity of delaying an investment to learn more about it before committing to the investment (e. g., Saya et al., 2010).

Framing: The way that information is presented, for instance, in terms of potential losses instead of possible gains (Tversky and Kahneman, 1981).
Growth options: The opportunity to pursue potential follow-on investments beyond what was initially anticipated (e.g., Saya et al., 2010).

Perceived contract clarity: The understandability of the contract and service level agreements (Heart, 2007).

Perceived cost effectiveness: The extent to which the benefit derived from the service is worth the cost invested (e.g., Saya et al., 2010).

\section{Technology characteristics}

Benefits - Access to specialized resources: Client's benefit from economies of skill by leveraging the skills, resources, and capabilities that the vendor offers (e.g., access to the latest technologies and IT-related know-how). These specialized capabilities could not be generated internally (Benlian and Hess, 2011).

Benefits - Availability: The benefit of the provider being able to provide better availability than the client itself (e.g., Gupta et al., 2013).

Benefits - Business performance improvement: A client organization's desire to increase overall business performance (i.e., effectiveness and efficiency through deployment) (Brcar and Bukovec, 2013).

Benefits - Flexibility: The benefits of increased flexibility due to the scalable, on-demand, and pay-per-use provisioning of IT resources and the trialability of services (Saya et al., 2010; Benlian and Hess, 2011).

Benefits - Focus on core competencies: The organization's ability to focus on core businesses activities (e.g., Benlian and Hess, 2011).

Benefits - Quality improvements: The motivation of the client organization to improve the quality and productivity of IT services by outsourcing to a third-party vendor. Clients expect providers to incorporate industry best practices and total quality management procedures, such as lean management concepts (Benlian and Hess, 2011), and to aim for various quality improvements, such as a faster response time to end-users or higher-quality user interfaces and features (e.g., Akhilesh, 2000).

Benefits - Reduced time to market: The organization's ability to deliver its products or services faster to the market when sourcing services externally (e.g., Seethamraju, 2013).

Benefits - Security: The benefit of the provider being able to provide better security than the client itself (e.g., Gupta et al., 2013).

Benefits - Transferring CAPEX to OPEX: The ability to optimize the use of IT resources by transferring fixed costs to variable cost (e.g., Baldwin et al., 2001).

Data destruction: The need for compliant and complete data destruction when switching providers (e.g., Brender and Markov, 2013).

Observability: The degree to which the impact of an innovation is observable to and can be communicated to others (Rogers, 1983).

Perceived benefits: The non-monetary benefits associated with the sourcing option that are not further specified or that are only defined in a generic manner (e.g., Lian et al., 2014).

Perceived complexity: The degree to which an innovation is perceived to be difficult to understand and use (Rogers, 1983). 
Perceived risks: The non-monetary risks associated with the sourcing option that are not further specified or that are only defined in a generic manner (e.g., Daylami et al., 2005).

Risks - Availability: The risk that services may not be available to the expected level of service (e.g., Benlian and Hess, 2011).

Risks - Business continuity: The risk of losing business continuity if the vendor fails to deliver the required service (e.g., Currie et al., 2004).

Risks - Loss of control: The risk of losing control or increasingly depending on the provider (Gorla and Lau, 2010).

Risks - Security: Security risks associated with remote data hosting, virtualized and shared resources, and data transfer over the Internet (Subashini and Kavitha, 2011).

Traceability and auditability: The ability to trace the history, location, or application of an item through recorded documentation (e.g., Morgan and Conboy, 2013).

\section{Client characteristics}

Age: Age of the company (e.g., Wholey et al., 2001).

Compatibility: The degree to which an innovation fits with the potential adopter's existing values, previous practices, and current needs (Rogers, 1983).

Desire to restructure the organization: An organizations desire to change the organizational structure in terms of the firm's management system, corporate culture, organizational boundaries, or bureaucracy (McLellan et al., 1995).

Financial leverage: The ratio to which a business uses debt $v s$ equity to fund investments (Hall and Liedtka, 2005).

Financial performance: The performance of the organization's financial resources (e.g., Teng et al., 1995).

Financial performance of IT function: The cost efficiency of an organization's IT function in terms of its contribution to overall corporate profitability (e.g., Loh and Venkatraman, 1992a).

Freeze of headcount: The client organizations management decision not to increase the employee headcount (e.g., Pinnington and Woolcock, 1995)

Industry: Industry of the organization (e.g., Yao et al., 2010).

Internal IT capabilities: The pool of resources, technical ability, expertise, knowledge, and skills available within the organization and their efficiency in developing, implementing, managing, and maintaining the organization's IT infrastructure and applications (Nam et al., 1996; Daylami et al., 2005).

IT budget: The budget allocated for IT relative to the organization's revenue (e.g., Li et al., 2006).

IT department age: Age of the IT department (e.g., Li et al., 2006).

IT department size: Size of the IT department (e.g., Gonzalez et al., 2005a).

Knowledge intensity: The degree to which the organization relies on and uses knowledge and information (Aubert et al., 2012).

National characteristics: Cultural characteristics of the client organization's nation (e.g., Dibbern et al., 2012).

New management forms: New management forms enabled by ITO (e.g., Dias Ferreira and Barbin Laurindo, 2009).

Outsourcing expertise: The level of management experience with outsourcing and the organization's capability to develop, manage, and maintain outsourcing relationships (Daylami et al., 2005; Gorla and Lau, 2010).

Power of IT department: The extent of the IT department's influence on important decision problems that are relevant to the department or corporate IT strategy (Nam et al., 1996).

Short-term cash needs: The organization's need for liquidity in the short term (Hall and Liedtka, 2005).

Size: The size of the client organization (e.g., Guenther and Tamm, 2002).

Strategic importance of IT: The degree to which IT is an integral part of the organization's corporate strategy and business success (Teng et al., 1995).

Strategic vulnerability: The risk that a company will lose critical resources and capabilities when sourcing assets from an external vendor (Loebbecke and Huyskens, 2006).

Strategy: An organization's competitive strategy according to Porter's (1998) three generic competitive strategies, namely, overall cost leadership, differentiation, and focus (e.g., Berg and Stylianou, 2009), or according to the aggressiveness strategies proposed by Miles and Snow (1978), namely, prospector, defender, analyzer, and reactor (e.g., Teng et al., 1995).

Supporting mobile workers: The client organization's desire to support mobile workers (Narasimhan and Nichols, 2011).

Top management support: The degree to which an innovation is supported by top management (e.g., Low et al., 2011).

\section{Individual characteristics}

Attitude toward outsourcing: The overall evaluative appraisal of an IS executive toward outsourcing (Benlian et al., 2009).

CIO skills: The decision maker's perception of the skills of the organization's CIO (Blaskovich and Mintchik, 2010).

Cognitive dissonance: The mental state that occurs if the results of a past decision fall short with the expectations that are tied to it (Vetter et al., 2011).

Congruence of personal goals: The degree to which the personal goals of the decision maker or political motivations within the organization are in line with outsourcing an asset (e.g., Hall and Liedtka, 2005).

Demographics - Age: The age of the decision maker (Li et al., 2006).

Demographics - Educational level: The formal education level of the decision maker (Li et al., 2006).

Demographics - Tenure: The number of years of the decision maker's affiliation with the organization (Li et al., 2006).

Internal communication: Internal communications at the personal level among managers in the organization ( $\mathrm{Hu}$ et al., 1997).

Personal risk preference: The degree of risk affinity of the decision maker (Vetter et al., 2011).

Personality traits - Conscientiousness: The degree to which an individual is achievement oriented, careful, hard working, organized, purposeful, persevering, responsible, and thorough (Li et al., 2006).

Personality traits - Extraversion: The degree to which a person is ambitious, active, assertive, gregarious, sociable, and excitement seeking ( $\mathrm{Li}$ et al., 2006).

Personality traits - Openness: Openness describes a person who is imaginative, creative, original, curious, sensitive, 
unconventional, flexible, broad minded, and adventurous (Li et al., 2006).

Prior outsourcing experience: The decision maker's past experiences with sourcing decisions for a specific asset (Vetter et al., 2011).

\section{Environmental characteristics}

Availability of skilled IT personal: The degree of availability of skilled IT personal on the market (e.g., Kern et al., 2002).

Capital intensity: The extent to which fixed assets are required for doing business in a given industry $(\mathrm{Qu}$ et al., 2011).

Competitive pressure: The level of pressure felt by the organization from competitors within the industry (Low et al., 2011).

Gross domestic product (GDP) per capita: GDP per capita in the client's country (Qu and Pinsonneauli, 2011).

Industry munificence: The extent to which an industry provides enough resources to support established organizations and new entrants and enables them to grow and prosper (Qu et al., 2011).

Institution-based trust: The degree to which the organization believes that effective third-party guarantees are in place to assure the fulfillment of the client's expectations (Gefen et al., 2006).

Institutional influences: Pressures for organizations to adjust their behaviors to conform to shared notions that may manifest as coercive, mimetic, and normative pressures (DiMaggio and Powell, 1983).

Institutional influences - Coercive: Both formal and informal pressures exerted on organizations by other organizations upon which they are dependent (e.g., laws, regulations, sanctions) (DiMaggio and Powell, 1983).

Institutional influences - Mimetic: Organizational responses to uncertainty by mimicking the behavior of others (e.g., competitors, experts, market leaders) (DiMaggio and Powell, 1983).

Institutional influences - Normative: Externally set norms, primarily stemming from professionalization (e.g., best practices, company internal IT principles, certification and accreditation, or compliance requirements) (DiMaggio and Powell, 1983).

Internet penetration: The percentage of Internet users in the population (Qu and Pinsonneauli, 2011).

IT intensity: The degree of how much an industry depends on IT (Qu et al., 2011).

Market maturity: The maturity of environmental conditions, such as technological maturity (e.g., Kishore et al., 2005) and legal maturity (i.e., the IT-related legal system is well developed and enforced (Qu and Pinsonneauli, 2011)), as well as the number, diversity, and reputation of viable vendors (e.g., Heart, 2010).

Shareholder expectations: The degree of fulfillment of shareholders expectations (e.g., Fiedler et al., 2013).

Sharing and collaboration: The desire to improve collaboration and promote openness both inside and outside the organization (Morgan and Conboy, 2013).
Social trust: The extent to which people trust in others in general (Qu and Pinsonneauli, 2011).

Trading partner requirements: The requirements of trading partners (e.g., Seethamraju, 2013).

Uncertainty: Unforeseen changes in the environment related to, for instance, technology (e.g., Ang and Cummings, 1997), demand (e.g., Aubert et al., 2012), requirements (Apte et al., 1997), contracts (Asatiani et al., 2014), and the like (Williamson, 1985).

Uncertainty - Behavioral: The risk that the provider acts opportunistically (Williamson, 1985).

Uncertainty - Demand: Uncertainty arising when parties do not know ex ante the exact volume of product that will be required or ignore the form that the service will take (Alaghehband et al., 2011).

Uncertainty - Product: Uncertainty concerning requirements specifications, delivery dates, costs, and information asymmetry problems that relate to the client's difficulty in evaluatings service and predicting how it will perform in the future (Dimoka et al., 2012).

Uncertainty - Technology: Rapid and unpredictable changes in technological developments (Alaghehband et al., 2011).

Uncertainty avoidance orientation: The extent to which people feel either uncomfortable or comfortable in novel, unknown, surprising, and unusual situations $(\mathrm{Qu}$ and Pinsonneauli, 2011).

\section{Vendor characteristics}

Current investment in IT: The vendor organization's current investments in IT (e.g., Berg and Stylianou, 2009).

Financial stability: The vendor's ability to stay financially viable (Currie et al., 2004).

Service capability: The vendor's ability to manage and deploy various tangible (e.g., physical IT infrastructure components, human IT resources) and intangible (e.g., knowledge assets, customer orientation) IT resources to provide the service (Bharadwaj, 2000). The capabilities are expressed by the vendor's expertise and knowledge about technology and processes, technical and managerial IT skills, and reputation as perceived by the client (e.g., Schwarz et al., 2009).

Support: The degree to which the vendor provides support to the client while evaluating, testing, and selecting services (e.g., Seethamraju, 2013).

Transferring risks to vendor: The benefit of transferring risks associated with owning and maintaining IT to the vendor (e.g., Baldwin et al., 2001)

Trustworthiness: The degree to which a client can place trust in a provider and remain confident that the trust shall not be betrayed (e.g., Berg and Stylianou, 2009).

Understanding company needs: The vendor organization's capability to understand the needs of the client, for instance, because of the vendor organization's expertise in business processes similar to those implemented within the client organization (e.g., Berg and Stylianou, 2009).

Willingness for value co-creation: The willingness of the vendor to closely work with the client and to create business value for both the client and the vendor (Seethamraju, 2013). 